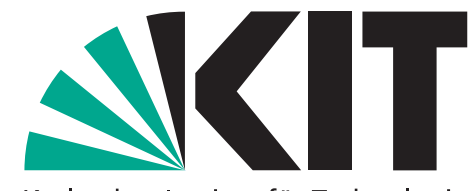

Karlsruher Institut für Technologie

\title{
Physical distance and cooperativeness towards strangers
}

by Leonie Kühl, Nora Szech

No. 110 | NOVEMBER 2017

\section{WORKING PAPER SERIES IN ECONOMICS}

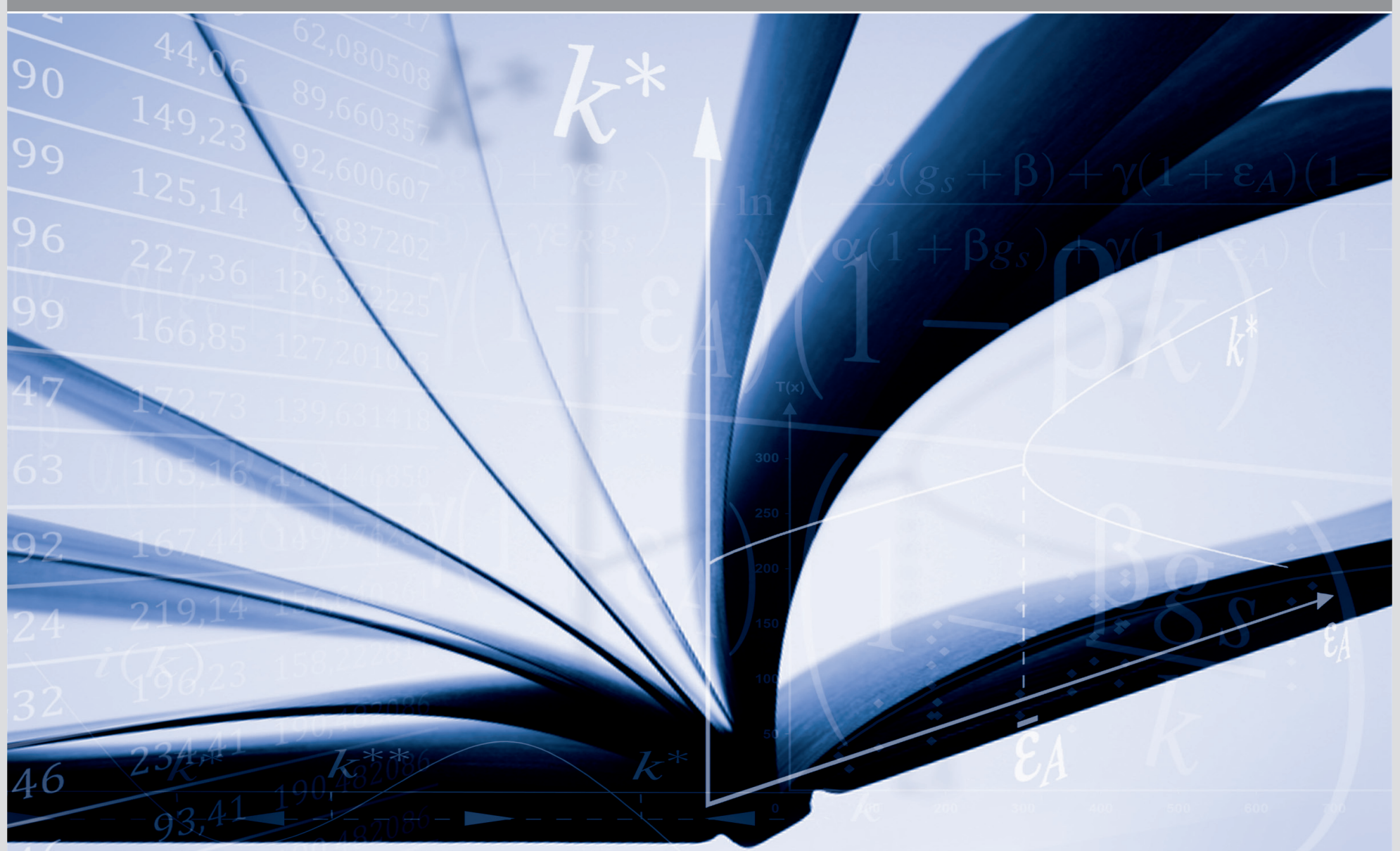




\section{Impressum}

Karlsruher Institut für Technologie (KIT)

Fakultät für Wirtschaftswissenschaften

Institut für Volkswirtschaftslehre (ECON)

Kaiserstraße 12

76131 Karlsruhe

KIT - Die Forschungsuniversität in der Helmholtz-Gemeinschaft

Working Paper Series in Economics

No. 110, November 2017

ISSN 2190-9806

econpapers.wiwi.kit.edu 


\title{
Physical Distance and Cooperativeness Towards Strangers
}

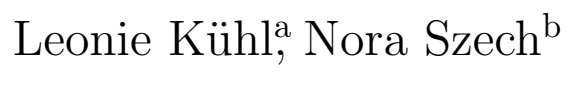

November, 2017

\begin{abstract}
Cooperativeness among genetically unrelated humans remains a major puzzle in the social sciences. We explore the causal impact of physical distance on willingness to help. In a field setting, participants decide about supporting local refugees at the dispense of money to themselves. We vary physical distance only, and keep other factors such as cultural distance fixed. The data shows that an increase in local physical distance decreases willingness to donate. A laboratory experiment confirms this finding. We further explore the causal roles of exposure (in the field) and of larger distances (in the lab) with a total of 475 participants.
\end{abstract}

${ }^{a}$ Leonie Kühl: Karlsruhe Institute of Technology, Institute for Economics, Chair of Political Economy, Fritz-Erler-Str. 1-3, 76133 Karlsruhe, Germany; leonie.kuehl@kit.edu.

${ }^{b}$ Nora Szech: Karlsruhe Institute of Technology, Institute for Economics, Chair of Political Economy, Fritz-Erler-Str. 1-3, 76133 Karlsruhe, Germany; CESifo, 81679 Munich, Germany; Berlin Social Science Center (WZB), 10785 Berlin, Germany; nora.szech@kit.edu 
Helping behavior in humans and animals is often explained by means of reciprocity, mutualism and manipulation towards kin and close members of the same social group (Clutton-Brock, 2009). Humans, however, also support non-kins and outgroup members ${ }^{1}$ Cooperativeness exists even under circumstances in which reciprocity (Trivers, 1971; Axelrod, 1981; Rabin, 1993; Hoffman et al., 1998; Nowak and Sigmund, 2005), reputational gain (McAndrew and Milenkovic, 2002; Ferrière, 1998; Soetevent, 2005), or signaling (Glazer and Konrad, 1996; Gneezy et al., 2012) cannot account for it (Fehr and Fischbacher, 2003). Identifying the mechanisms responsible for this willingness to provide support remains a major task in the social sciences as well as in the natural sciences (Van Vugt and Van Lange, 2006).

This study focuses on the causal role of physical proximity for supporting genetically non-related humans in local neighborhoods. If local physical distance has an impact, it may be relevant for many situations in which humans interact. Potentially, many pressing social problems could be overcome through cooperation. Therefore, the magazine Science has proposed that understanding and fostering cooperativeness should be one of the most important research questions in the upcoming decades ${ }^{2}$ Related disciplines such as social psychology have discussed physical distance as causal for morally relevant behavior and misbehavior. Models of cooperativeness towards non-kins often stress physical proximity as a major driver (Bandura, 1999; Jones, 1991). Yet empirical evidence so far relies on case studies without clear counterfactual (Grossman, 2009), questionnaires (Fessler et al., 2015), or staged scenario studies without real consequences (Milgram, 1974). In a related vein, military organization suggests that an increased physical distance lowers moral conflict in soldiers (Grossman, 2009; Gray, 1999). Yet again, there exists no controlled evidence involving real behavior.

From a political point of view, the question of how to foster helping behaviors in humans who live close by may become especially pressing. As one concrete example, since 2015, more than two million refugees and migrants have fled into Europe, trying to escape war, violence, and poverty in their home countries. Matters culminated to the refugee crisis, challenging politics, as well as societies of destination countries. Germany, which took a prominent role in welcoming refugees, now needs to cope with more than 700.000 new asylum seekers from 2016 alon $\$^{3}$. While the vast majority of Germans ini-

\footnotetext{
${ }^{1}$ Compare e.g. the !Kung foragers of Namibia (Bowles, 2008) or the Arapesh of New Guinea (Mead, 2002).

${ }^{2}$ Compare Science (2005).

${ }^{3}$ Compare e.g. Eurostat (2017)
} 
tially supported the influx of refugees 4 , it became challenging to find suitable shelters logistically, but also from a social point of view. Residents expressed concerns about negative impacts from shelters in their direct proximity 5 .

Local proximity may be specifically important for human cooperation. From an evolutionary perspective, humans seem to be trained to focus on people in their direct proximity. It has been shown that parochialism plays a crucial role for activating helping behaviors (Fessler et al., 2015; Bowles and Gintis, 2004, Bernhard et al., 2006). Physical proximity may be a driver for this effect. We employ a field and a laboratory study with a total of 475 participants in order to investigate how local, physical distance affects the willingness to support other, non-related humans. In our field study (Refugee Paradigm), participants all start at the same premises at the Karlsruhe Institute of Technology (KIT), then walk about one mile to different locations of cubicles on campus, depending on treatment. These cubicles are either 0.2 miles or 2 miles away from the same refugee camp. From their cubicles, participants decide if they want to share 15 euro with refugees from that camp, or not. They know that if they decide not to share, they keep all the money. Our design makes it possible to isolate physical distance, i.e. we keep other aspects such as visibility of the refugee camp constant. The data demonstrates that closer physical proximity causally increases the willingness to share the money with refugees ${ }^{6}$

Our findings on local physical proximity are corroborated by a laboratory study (Charity Paradigm) in which participants donate for charity. We vary how physically far away these charities are, keeping other aspects such as the purpose of charity as comparable as possible. The data confirm that local increases in physical distance (from 0.2 to 0.6 to 2 miles) cause significant reductions in willingness to provide support. Furthermore, in this setting, we can also explore the impact of larger distances.

Several motivations for helping behaviors and charitable giving have been discussed in economic research (compare e.g. Meier (2006)). Self-interest, altruism, a "warm-glow" from giving, a general morality in humans Andreoni, 2006), social rules and norms as well as reciprocity (Vesterlund, 2006), but also self-image and reputation (Bénabou and Tirole, 2010) can be important drivers for charitable giving and prosociality. But not only in the field of economics, also in sociology, business management and marketing and even biology, researchers have tried to identify several mechanisms or factors that

\footnotetext{
${ }^{4}$ Compare e.g. BAMF Bundesamt für Migration und Flüchtlinge (2016); The Economist (2005)

${ }^{5}$ Compare e.g. Süddeutsche Zeitung (2014); Die Zeit (2016)

${ }^{6}$ We explore the impact of direct exposure in a third treatment.
} 
affect or predict the extent and type of giving (Bekkers and Wiepking, 2011).

The institutional environment can influence behavior and charitable giving extensively (Meier, 2006, Andreoni and Serra-Garcia, 2016). Providing social information about others' contribution can affect giving (compare e.g. Frey and Meier (2004); Krupka and Weber (2009); Shang and Croson (2009)). Information about the situation itself (directly or indirectly transported e.g. via exposure), might change the assessment and perception of the need and impact of donations (Bekkers and Wiepking, 2011; Cryder et al., 2013). This information or exposure can potentially increase helping behavior due to sympathy and affect (Burnham, 2003; Dickert and Slovic, 2009) but also reduce supporting behavior when it triggers negative feelings (Isen and Noonberg, 1979), overload (Eckel et al. 2007) or when it creates a feeling that the situation is hopeless and a donation would only be a "drop in the bucket" (Small et al. 2007).

Moreover, tangibility has been discussed to affect generosity and charitable giving. Information that is more concrete and psychologically nearer ${ }^{7}$ may be processed differently, i.e. more concretely, resulting in higher levels of emotional response (Cryder and Loewenstein, 2010; Cryder et al., 2013). Furthermore, it has been shown that generosity increases when a recipient of aid is determined and identifiable and thus is no longer a statistical and abstract entity (compare e.g. Loewenstein (2003)). All these mechanisms may play additional roles in situations in which physical distance varies as well. Our study demonstrates that even if these other mechanisms are absent, local physical distance has causal impact on willingness to provide support.

Another potentially important mechanism may be the expected and perceived impact of a donation or supporting behavior (Trussel and Parsons, 2007) as well as the awareness and sense for a need to begin with (Lee and Farrell, 2003). The expected and perceived impact of donations can differ between different causes or destinations but also between specific charities for the same cause. Helping and giving behavior can be influenced by the perceived impact e.g. due to considerations regarding trust, competence and corruptibility of the respective institution (Uslaner, 2004). Our field study has the advantage that it keeps the party in need constant. The only aspect that varies is physical distance. If beliefs about worthiness of receiving a donation vary, physical distance must be the causal source of these belief changes across treatments. Our laboratory study, in which destinations of charity vary, confirms that physical distance also plays a causal role when it comes to largely comparable parties in

${ }^{7}$ Psychological distance here refers to temporal, spatial or social distance (compare e.g. Liberman et al. (2007)). 
need, even if they are not identical. Local physical distance thus seems to be an important source of generosity and cooperation. In contrast, increases of distance in local neighborhoods (as from 0.2 to 0.6 to 2 miles) causally reduce willingness to cooperate in unrelated humans.

\section{Design of Experiment and Hypothesis}

In this section, we motivate and describe the design of our two studies and the according hypotheses. First, we describe the design of the field study, which employs a paradigm that involves refugees from a local refugee camp in Germany. The decision in the Refugee Paradigm is kept as easy as possible in the sense that participants can either split their monetary amount in half and thereby share with refugees, or keep the entire amount to themselves. We do so in order to foster a sense of moral relevance (compare e.g. Smith et al. $(2013))$. Second, we present the design of our laboratory study. In the latter, participants decide if and how much they want to donate for charity. In the Charity Paradigm, we expand the options using a price list instead of a binary decision and we also explore destinations very far away from participants. We try to keep charities involved as comparable as possible across treatments and let physical distance to participants vary, on a smaller local, and on a larger scale. Yet of course, in the Charity Paradigm, this is a challenge, while in the Refugee Paradigm, all donations always go to the same destination, the refugee camp in Karlsruhe.

\subsection{The Refugee Paradigm}

This field study investigates the causal role of physical proximity for human cooperativeness towards refugees in a real, controlled situation. Motivated by the European refugee crisis, we focus on the causal effects of physical proximity and direct exposure on individual willingness to monetarily support refugees. 9 To the best of our knowledge, this study is the first to uncover causal effects

\footnotetext{
${ }^{8}$ For a general economic understanding of mechanisms affecting philanthropy, see Andreoni et al. (2017) and Andreoni (2015) and the references therein.

${ }^{9}$ Several economic studies analyze institutional effects on cooperation, typically with a focus on cooperation within groups. For example, Fehr and Schmidt (1999) and Henrich et al. (2001) analyze the effects of norm enforcement. See Axelrod (1981) for an evolutionary approach towards the development of prosociality and cooperation, and Henrich et al. (2001) for attempts at identifying cultural and socio-economic aspects fostering cooperation. Falk and Szech (2013) and Kirchler et al. (2015) analyze institutional effects on moral behaviors.
} 
of physical proximity on cooperativeness in a real, controlled situation, i.e. in an economic field study. 10

In order to identify whether physical distance can causally affect helping behaviors towards non-kins, we propose the Refugee Paradigm. This paradigm has three major advantages: First, it allows for a clean counterfactual, which is needed in order to determine causal effects. Second, it focuses on decisions that involve real consequences. Third, participants know that there is no possibility to gain reputation or reciprocal advantages through being generous.

Physical distance may involve direct exposure or not. Therefore, we implement three treatments: Distance, Proximity, and Exposure. In all treatments, participants decide about keeping 15 euro to themselves versus sharing these 15 euro with refugees from a local refugee camp ${ }^{11}$ Thus statistically, comparable participants decide about donating money to the same camp. To vary physical distance across treatments, participants decide at different places. All participants are invited to a meeting point. There, they are individually, one by one, handed out maps that guide them to the respective premises according to the randomly determined treatment. ${ }^{12}$ The premises of the study are either about 0.2 miles away from a local refugee camp (in the Proximity treatment and the Exposure treatment), or about 2 miles away from the refugee camp (in the Distance treatment). To implement direct exposure, participants in the Exposure treatment follow a route that goes partly along the refugee camp on their way to the study. Compare Figure 1 and Table 1 for an overview of the different routes and treatments.

There was no drop-out between registering at the meeting point and reaching the assigned destination. When participants arrive at the respective premises, they one by one register and are then placed into cardboard cubicles. Then they are individually and anonymously confronted with the decision to allocate 15 euro between themselves and refugees from a local refugee camp. The choice is binary, such that participants can either keep the 15 euro entirely, or share the money with the refugee camp. In the latter case, they know that they will receive only 7.50 euro for themselves. The other half of the money will be used to support refugees. Incentivizing this decision is important in order to study real behavior in contrast to hypothetical claims (compare e.g. Falk and Heckman (2009) ). In a non-incentivized questionnaire, for example,

\footnotetext{
${ }^{10}$ For the necessity of controlled, incentivized studies in the social sciences, see Charness and Fehr (2015).

${ }^{11}$ Given the challenging situation in Germany at that time, it was clear that any kind of support was more than needed (Brücker et al., 2015).

${ }^{12}$ We tried to set routes and locations as comparable as possible, for more detail see appendix.
} 
it is comparatively cheap to state that one would like to share money.

After this main decision, each participant takes part in an ex post sociodemographic questionnaire. Participants know that monetary amounts are submitted in sealed envelopes such that neither the present experimenters nor other participants could know about their decisions. Participants always know their decisions and payments are treated anonymously. All participants know that the money benefits refugees from a local camp. According to treatment, we vary physical distance and prior direct exposure towards this camp when the decision is taken. When allocating the money, participants know from the instructions how physically close the refugee camp is. This is specifically important in the Distance treatment and the Proximity treatment as participants do not see the refugee camp on their way to the study's premises. There, we focus on the pure impact of physical distance alone. Most participants had not seen the camp before, and thus had no idea what it looks like.

The study took place in November 2015 at and around the campuses of a German university. At that point in time, the refugee crisis was in full bloom. It was thus salient that any kind of support would be more than welcome. A total of 155 participants (59\% males) took part in the study. Participants were recruited out of a mixed student sample at the Karlsruhe Institute of Technology (KIT) in Germany using the software ORSEE (Greiner, 2015). Overall duration per session was about 90 minutes. For more detail and references, see the appendix. 


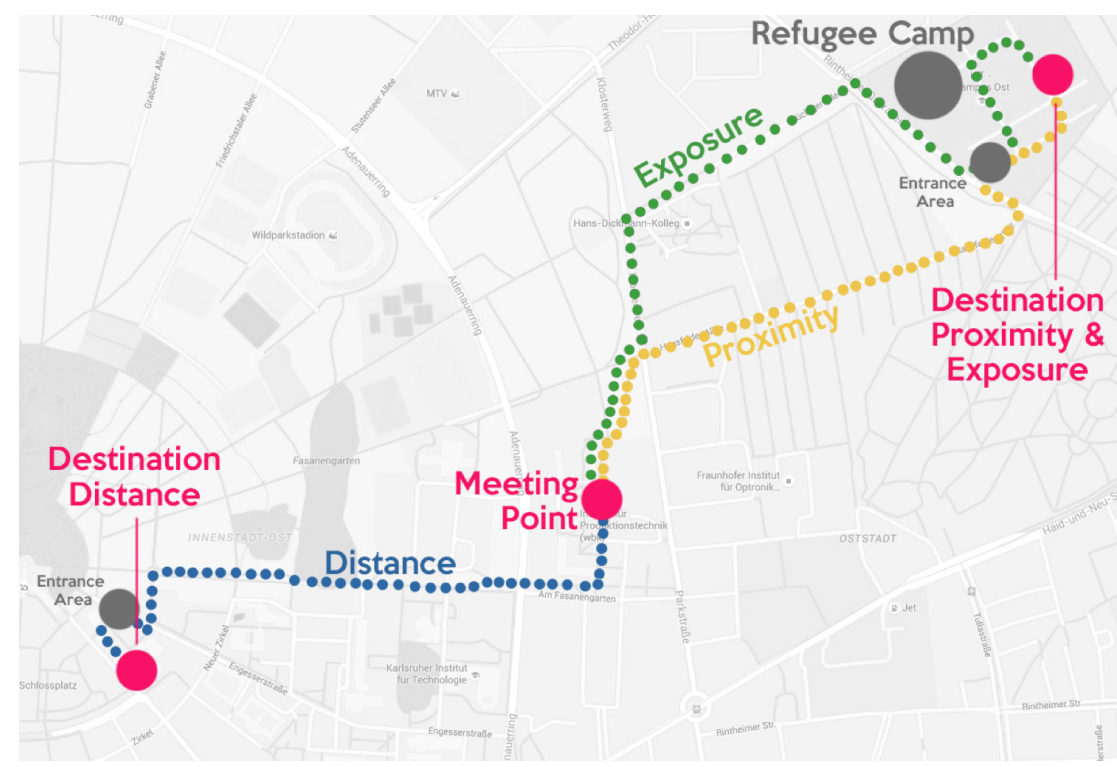

Figure 1: Overview map with locations and routes for all treatments. In all treatments, participants are invited to the meeting point from where they followed different routes to the respective premises of the study.

\begin{tabular}{c|c|c}
\hline Distance & Proximity & Exposure \\
\hline $\begin{array}{c}\text { camp is about } \\
2 \text { miles away }\end{array}$ & $\begin{array}{c}\text { camp is about } \\
0.2 \text { miles away }\end{array}$ & $\begin{array}{c}\text { camp is about } \\
0.2 \text { miles away }\end{array}$ \\
\hline $\begin{array}{c}\text { no direct exposure } \\
\text { to the refugee camp }\end{array}$ & $\begin{array}{c}\text { no direct exposure } \\
\text { to the refugee camp }\end{array}$ & $\begin{array}{c}\text { direct exposure } \\
\text { to the refugee camp }\end{array}$ \\
\hline $\mathrm{n}=49$ & $\mathrm{n}=55$ & $\mathrm{n}=51$ \\
\hline
\end{tabular}

Table 1: Overview of treatments in the Refugee Paradigm. Treatments vary aspects of physical proximity during a sharing decision and prior exposure to a refugee camp.

We hypothesized that participants would feel more involved and thus would be more likely to share in physical proximity than in physical distance. Effects of physical distance have been discussed in the social sciences (Bandura, 1999, Jones, 1991; Milgram, 1974), but also in applications such as military organization, where physical remoteness of victims, and weapons allowing for such remoteness, are characterized as important means to lower feelings of responsibility and moral conflict (Grossman, 2009; Gray, 1999). With regard to direct exposure, cooperativeness may increase or decrease, depending on whether 
feelings of similarity and empathy, or rather aversive feelings, e.g. driven by ingroup-outgroup biases or personal overload, become activated (Bandura, 1999; Nisbett and Ross, 1980). Therefore, while we hypothesized a higher willingness to share in Proximity versus Distance, effects of direct exposure were less clear. It could have been that participants felt even more responsible and donated more in case of direct exposure, yet only if no aversive reaction was provoked by seeing the camp and the refugees directly.

Focusing on the effects of physical distance versus proximity alone, we thus expected for the fraction of participants willing to share their money (which we define as Willingness to Share) that

$$
\text { Willingness to Share } \text { Proximity }>\text { Willingness to } \text { Share }_{\text {Distance }} \text {. }
$$

In the Proximity treatment, there is no direct exposure to the refugee camp. The Exposure treatments adds such direct exposure while keeping physical distance fixed compared to the Proximity treatment. Therefore, comparing the Proximity and the Exposure treatment allows us to isolate effects of direct exposure in this context. We considered this comparison as an important explorative one as often, an increased physical proximity may ultimately result in a situation of direct confrontation:

$$
\text { Willingness to Share } \text { Exposure }>?<\text { Willingness to Share } \text { Proximity }_{\text {. }}
$$

\subsection{The Charity Paradigm}

In this laboratory study, we invite participants to the KD2-lab in Karlsruhe. Our goal is to replicate the findings from the Refugee Paradigm that locally, physical distance reduces cooperativeness. We therefore set up three more local treatments in which participants decide over the allocation of a 15 euro endowment between themselves and a charity for people in need. Participants know that they keep the rest of the money. In all treatments, the purpose of charity is to support people in need with food or shelter.

These treatments operate with the same distances as in the Refugee Paradigm, i.e., 0.2 and 2 miles. We add one more treatment in order to integrate an intermediate distance of 0.6 miles. Table 2 provides an overview of the three treatments in the Charity Paradigm. 


\begin{tabular}{c|c|c}
$0.2 \mathrm{mi}$ & $0.6 \mathrm{mi}$ & $2 \mathrm{mi}$ \\
\hline \multicolumn{3}{c}{ local } \\
(within the same city) \\
\hline $\mathrm{n}=40$ & $\mathrm{n}=40$ & $\mathrm{n}=40$
\end{tabular}

Table 2: Overview of the Charity Paradigm treatments (local distances). Treatments vary physical distance while deciding over sharing money with people in need.

In the Charity Paradigm, the destination of the money donated varies. We tried to keep charities as comparable as possible across treatments, yet of course, charity organizations have to vary to some extent. In this regard, the Refugee Paradigm allows us to isolate the causal impact of local, physical distance in a neater way: the destination of donations stay constant across treatments. For the local treatments in the Charity Paradigm, we nevertheless expect to replicate the findings from the Refugee Paradigm. All charity organizations involved serve a comparable purpose (food or shelter for people in need), and all charities are located in Karlsruhe. We thus hypothesize that

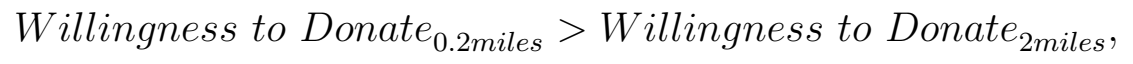

equivalent to the Refugee Paradigm. Furthermore, for the new treatment with a physical distance of 0.6 miles, we expect to see our general local pattern confirmed, i.e.,

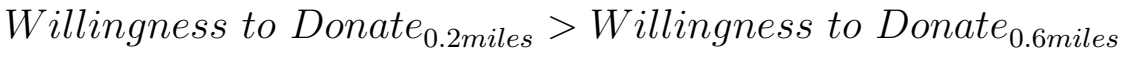

$$
\begin{aligned}
& >\text { Willingness to } \text { Donate }_{2 m i l e s} \text {. }
\end{aligned}
$$

\subsection{Exploring the Charity Paradigm in Large Distances}

To explore the causal impacts of larger physical distances on cooperative behavior, we introduce five treatments that implement the distances of about 6 miles, 20 miles, 60 miles, 600 miles and 6,000 miles. In these five treatments, our goal is to explore the impact of intermediate and large physical distances that go beyond local neighborhoods. In order to keep the impact of charity as comparable as possible, the instructions inform participants that destinations where the charity organizations operate are economically comparable to Karlsruhe. In the instructions, we stress that the "money will benefit people in need in a city with comparable prosperity like Karlsruhe (according to 
unemployment rate and GDP per capita of the respective region)". Table 3 provides an overview of the five treatments of our explorative study.

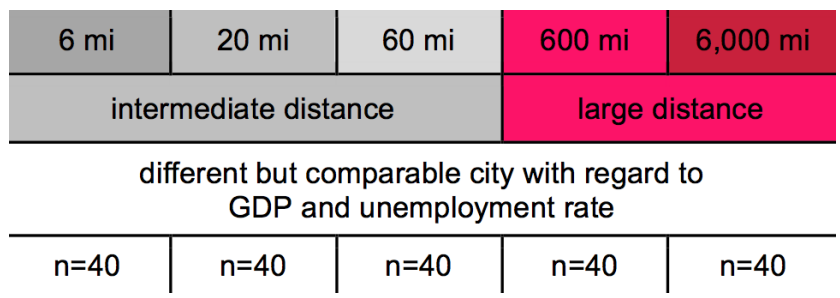

Table 3: Overview of the Charity Paradigm treatments (intermediate and large distances). Treatments vary physical distance while deciding over sharing money with people in need in comparable cities.

For the larger distances, we are less sure to see the same pattern. We try to evoke an impression of comparability of effectiveness of donations. This is also stressed in the instructions. Yet of course, findings hinge on whether participants fully digest this information. If so, we expect a reduction in willingness to donate as physical distance increases further:

Willingness to Donate $_{\text {intermediate distance }}>$ Willingness to Donate $_{\text {large distance }}$.

Data from the Refugee Paradigm suggests that gender may play an important role when it comes to willingness to donate. We therefore run the Charity Paradigm in a gender-controlled way, inviting comparable numbers of males and females to the study. Among participants, we achieve an almost balanced proportion of $55 \%$ males and $45 \%$ females. The study took place between March and May 2017 with a total of 320 participants who were randomized into the different treatments (eight treatments in total).

\section{Results and Discussion}

This section presents the results of both studies. We find in both settings that increasing physical distance in a local environment decreases willingness to provide support. The Refugee Paradigm allows us to further investigate the causal role of direct exposure to people in need. We find that exposure to refugees decreases willingness to donate. In an ex-post analysis, we see that this effect is entirely driven by males. Potentially, aversive reactions become activated in male participants when seeing refugees in need as those refugees are mostly young males. In the Charity Paradigm, we replicate the causal impact of local proximity. The findings on local distances from the Refugee 
Paradigm are further backed up by the new intermediate treatment of 0.6 miles. Locally, an increase in physical distance reduces willingness to provide support. Further, we explore the causal impact of larger physical distances (up to 6,000 miles) on willingness to donate. Our data display a structural break between local distances (up to 2 miles) and larger distances (up to 6,000 miles). On a local level, distance matters significantly. This is not the case with distances far away, even if they vary 10 times. In an ex-post analysis, we find that participants feel less responsible towards people in need that are further away but increasingly refer to general norms to explain their behavior. It is thus likely that even though the instructions informed participants that economic conditions in the destinations were basically comparable to those in Karlsruhe, participants perceived and handled the decision differently.

\subsection{Results: Refugee Paradigm}

In the Refugee Paradigm, participants decide about donating to a local refugee camp. In the Distance and Proximity treatments, participants decide without having seen the refugee camp along their way to the study's premises. The vast majority of participants had not seen the camp either in any other situation before the study took place, see appendix for details. As hypothesized, physical proximity increases cooperativeness expressed in willingness to donate money to the camp compared to the Distance treatment, see Figure 2. More participants are willing to donate if the refugee camp is physically closer. Willingness to donate increases significantly, by $41 \%$, in Proximity compared to Distance ( $\mathrm{p}=0.048$, one-sided chi-squared test, $\mathrm{n}=104)$. In both treatments, participants have not been directly exposed to the refugee camp on their way to the study. Yet they know that refugees are physically close in Proximity. Our data, thus, reveal that local proximity is an important mechanism causally increasing cooperativeness towards strangers in need. Overall willingness to support refugees was already pronounced in the Distance treatment. Nevertheless, a significant increase results from proximity. 


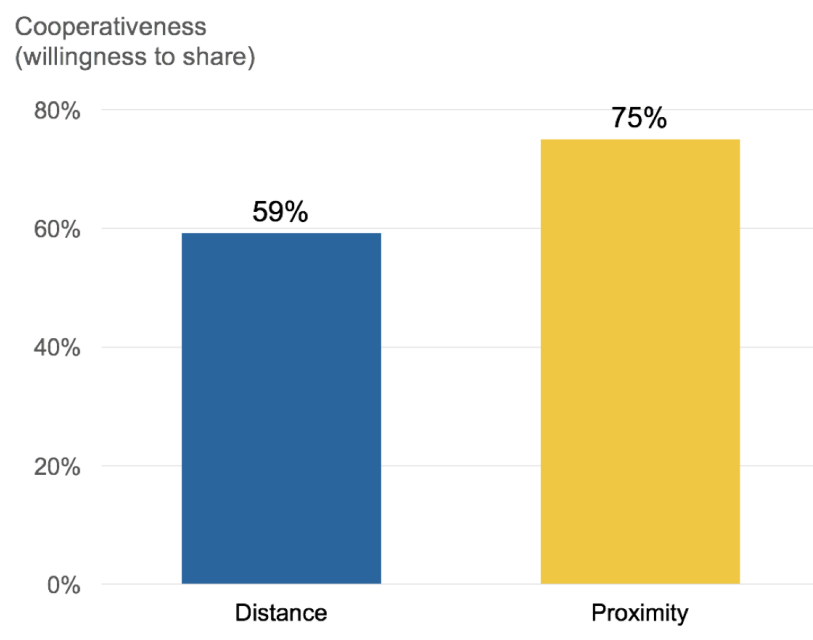

Figure 2: Willingness to share in the treatments Distance and

Proximity. Physical proximity increases cooperativeness: In Proximity, significantly more participants share their money with refugees ( $75 \%$ vs. $59 \%$, $\mathrm{p}=0.048$, one-sided chi-squared test, $\mathrm{n}=104$ ).

Comparing the Proximity with the Exposure treatment allows us to isolate the causal effect of direct exposure. In both treatments, participants know that the camp is in close physical distance (about 0.2 miles away). Yet in Exposure, participants have followed a route passing the refugee camp on their way, which has not been the case in the other treatments. Participants could thus see the camp and the people living there. This may transport additional information, but also evoke different feelings towards refugees, activate helping behaviors or increase aversive reactions.

The behavioral data reveal a pronounced reduction in willingness to share in Exposure compared to Proximity $(\mathrm{p}=0.034$, two-sided chi-squared test, $\mathrm{n}=106$ ), see Figure 3. Via direct exposure, willingness to share drops back to a level statistically comparable to the Distance treatment. Direct exposure here counteracts the pure effect of physical proximity. Willingness to share in Exposure is at any conventional level statistically comparable to the Distance treatment $(\mathrm{p}=0.665$, two-sided chi-squared test, $\mathrm{n}=100)$. In the data, effects of proximity and exposure offset each other. 


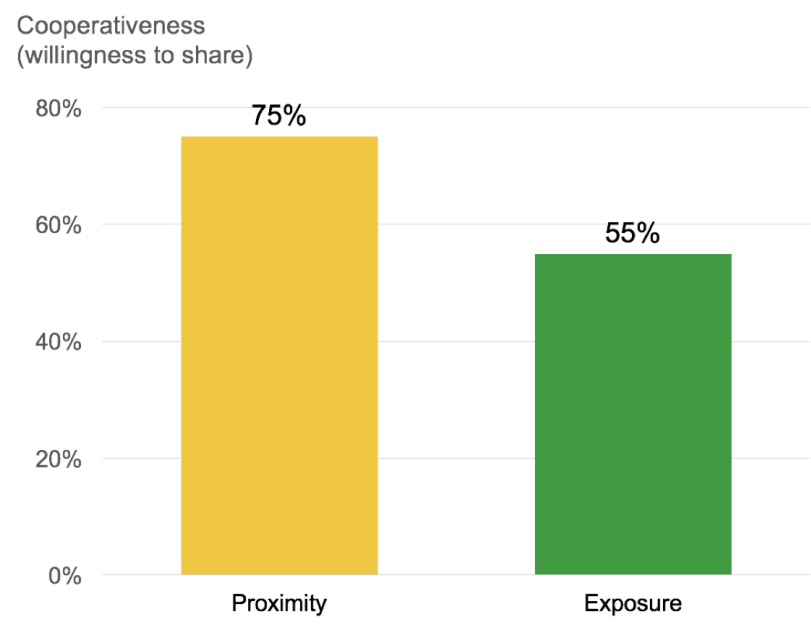

Figure 3: Willingness to share in the treatments Proximity and

Exposure. In Exposure, significantly less participants are willing to share their money compared to Proximity ( $55 \%$ vs. $75 \%, \mathrm{p}=0.034$, two-sided chi-squared test, $\mathrm{n}=106)$.

Across all treatments, we observe a rather strong cooperativeness towards refugees. Participants are mostly students who do not dispose of much money themselves. (Mean disposable income per month (without housing) amounts to 384 euro.) Nevertheless, in all treatments, the majority of participants is willing to donate half their money to refugees. Through physical proximity, this willingness increases to three out of four participants opting to share their money. Physical proximity fosters supporting behaviors as long as the refugee camp remains a rather abstract entity ${ }^{13}$ When directly exposed to the camp, willingness to donate decreases, to a level comparable to the Distance treatment.

Data from our post experimental questionnaire reveal that participants who decide to share their money feel good. Over all treatments, we find a highly significant difference in happiness for those who donated (measured in a 5point-scale), both right after the decision and at the end of the study $(\mathrm{p}<0.01$, two-sided t-test, respectively). Further, when asked hypothetically, only 5 out of 155 participants (two sharers and three non-sharers) prefer to reverse their sharing decisions ex post. These findings suggest that participants took their decisions considerately.

Cooperativeness is in line with general personality traits: Compassionate $(\mathrm{p}<0.05$, one-sided t-test), agreeable $(\mathrm{p}<0.01$, one-sided t-test $)$ and open-

\footnotetext{
${ }^{13}$ Almost all participants of the study had not seen the camp before $(82 \%)$.
} 
minded ( $\mathrm{p}<0.05$, one-sided t-test) participants are more likely to share their money with refugees. Participants in favor of military intervention regarding the refugee crisis opt less likely for sharing $(\mathrm{p}<0.01$, one-sided t-test). Our data thus provide convergent and discriminatory validity of decisions taken in the Refugee Paradigm. Participants in Exposure do not feel better informed when taking their sharing decision, as we deduce from our ex post questionnaire. If anything, the opposite is the case $(\mathrm{p}=0.11$, two-sided t-test, Proximity vs. Exposure). Furthermore, we do not find a correlation between the perceived level of information and willingness to share ${ }^{14}$

Looking into effects of gender, in an ex post analysis, male participants react stronger to direct exposure. Males tend to reduce their willingness to donate more than females ( $\mathrm{p}=0.089$, diff-in-diff of males vs. females in Proximity vs. Exposure), ending up at a significantly lower level of cooperativeness in the Exposure treatment than females ( $\mathrm{p}=0.031$, two-sided chi-squared test) (see Figure 4). In contrast, gender differences in Distance and Proximity and the respective diff-in-diff measures are not statistically significant at any conventional level. The data reveal that the comparably low cooperativeness in the Exposure treatment is almost entirely driven by male participants. 15

\footnotetext{
${ }^{14}$ For details and further findings, see appendix.

${ }^{15} 59 \%$ of all participants were males ( $\mathrm{n}=32$ males in Distance, $\mathrm{n}=32$ males in Proximity, $\mathrm{n}=27$ males in Exposure).
} 


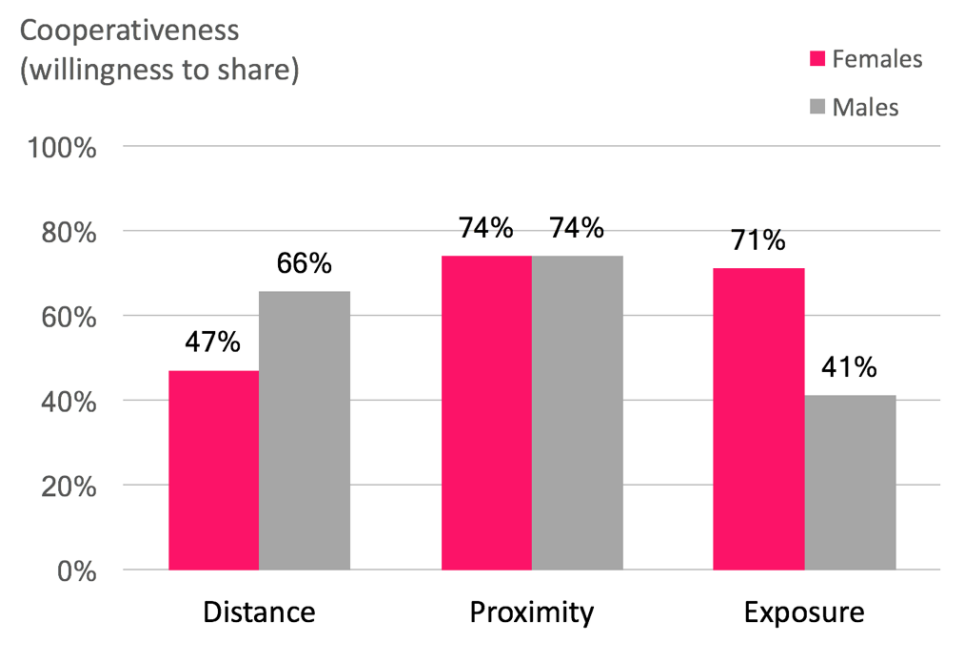

Figure 4: Interaction of gender, distance and exposure in affecting willingness to share. In Exposure, males tend to reduce their willingness to share significantly more than females $(\mathrm{p}=0.089$, diff-in-diff, $\mathrm{n}=105)$. In Distance, there is no statistically significant difference in cooperativeness (on any conventional level).

Participants neither choose the treatment they are in, nor do they choose their gender. Therefore, both variables can be treated exogenously and independently. While this study is not a primarily gender-oriented study, the findings suggest that effects of direct exposure may differ among subgroups of a population. The finding is in line with a rich literature documenting that males and females react differently to (social) cues (e.g. Rigdon et al. (2009); Croson and Gneezy (2009); DellaVigna et al. (2013)). Males tend to be more social dominance-oriented, reacting more strongly to (perceived) outgroup threat than females (Vugt et al., 2007; Pratto et al., 1994). Such group dominance behavior can be even stronger when outgroup members are males (Navarrete et al. 2010), as is the case in our setting as well ${ }^{16}$ Also, males tend to have stronger ethnocentric attitudes than females (e.g. Sidanius et al. (1991) and the references therein).

In our ex-post questionnaire, we ask participants for personal relations with refugees and prior experience with flight or refugees within the family. We find a significantly lower cooperativeness for participants with personal relations, family links and experiences with refugees $(\mathrm{p}=0.022$, two-sided t-test, $\mathrm{n}=155)$.

\footnotetext{
${ }^{16}$ Compare description and picture of the refugee camp in the appendix (section 1.3 . Figure 17). In 2016, the vast majority of the current refugees (67 \%) are males (Eurostat, 2017).
} 
Yet again, this difference is entirely driven by males $(\mathrm{p}=0.005$, two-sided $\mathrm{t}$ test, $\mathrm{n}=91$ males, $\mathrm{p}=0.944$, two-sided t-test, $\mathrm{n}=64$ females). Although our experiment covers only a one-shot situation, these findings suggest that gender differences regarding exposure might persist over time.

\subsection{Results: Charity Paradigm}

The purpose of the Charity Paradigm is to a) replicate the findings of local, physical distance affecting cooperativeness, and b) to explore the causal impact of larger physical distance on willingness to provide monetary support. We therefore focus first on variations in local, physical distance. As in the Refugee Paradigm, we employ a physical distance of 0.2 and 2 miles. In order to gain additional insight, we add a third treatment with a physical distance to the charity organization of 0.6 miles. We expected to see a reduction in willingness to donate as local physical distance increases. This is exactly what we find (compare Figure 5). Willingness to donate decreases significantly with increasing distance on a local level (5.95 euro in $0.2 \mathrm{mi}$ vs. 3.54 euro in $2 \mathrm{mi}$, two-sided t-test, $\left.\mathrm{p}=0.01^{* *}, \mathrm{n}=80\right)$.

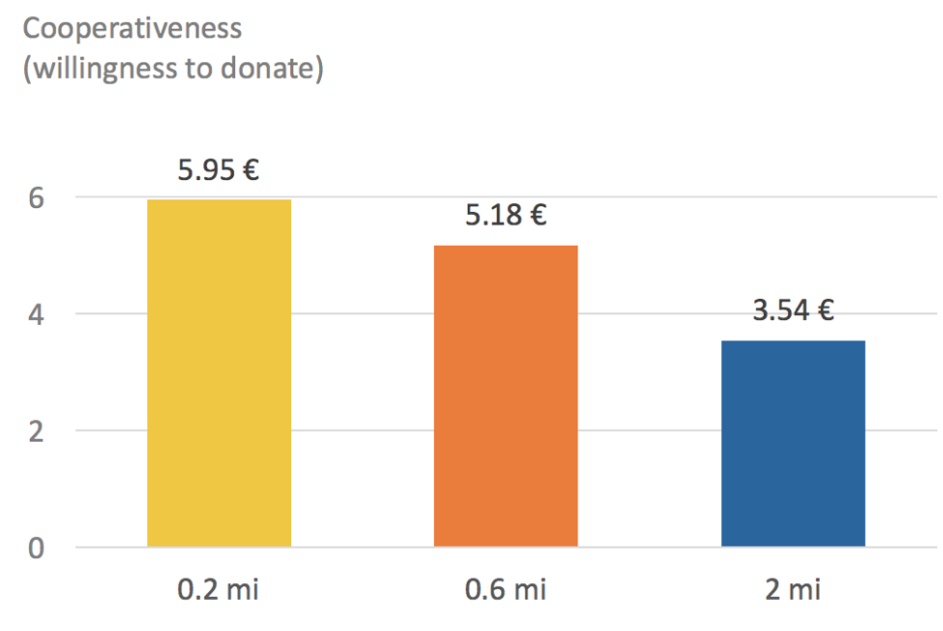

Figure 5: Willingness to donate in the lab. As in the field, increasing physical distance from 0.2 up to 2 miles reduces willingness to donate (mean donation of 5.95 euro vs. 3.54 euro, two-sided t-test, $\mathrm{p}=0.01^{* *}, \mathrm{n}=80$ ).

Differentiating for gender, we see that overall willingness to donate is less pronounced in males (6.04 euro in females vs. 4.06 euro in males, two-sided ttest, $\mathrm{p}=0.02^{* *}, \mathrm{n}=120$ ), yet differences across the 0.2 and the 2 miles treatment are comparable across gender (all three diff-in-diff measures for 0.2 vs. 0.6 
miles, 0.6 vs. 2 miles and 0.2 vs. 2 miles are not statistically significant with $\mathrm{p}=0.41, \mathrm{p}=0.43$ and $\mathrm{p}=0.92$ and $\mathrm{n}=80$ each).

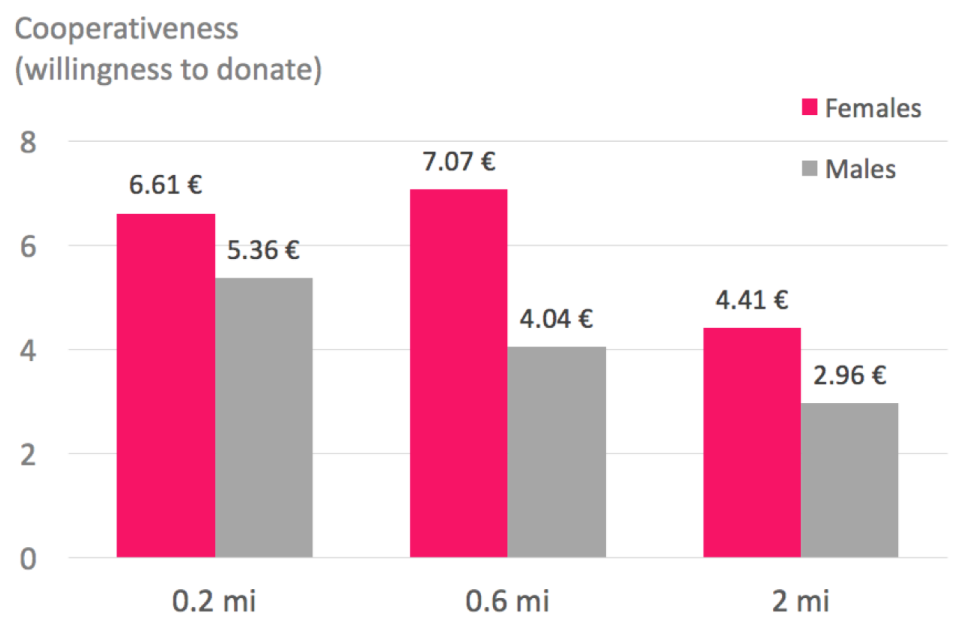

Figure 6: Gender differences in willingness to donate. Overall, females donate significantly more than males (6.04 euro vs. 4.06 euro, two-sided t-test, $\left.\mathrm{p}=0.02^{* *}, \mathrm{n}=120\right)$.

\subsection{Results: Large Distances}

Varying physical distance of destinations outside of Karlsruhe seems to have a different impact on donation behavior. Nonlocal donation behavior seems to be unaffected by variation of physical distance. We do not find any significant difference between the willingness to donate in intermediate or large distances, as depicted in Figure 7 (5.34 euro in intermediate vs. 5.90 euro in large distances, two-sided t-test, $\mathrm{p}=0.409, \mathrm{n}=200$ as well as 4.59 euro in $6 \mathrm{mi}$ vs. 5.76 euro in $6000 \mathrm{mi}$, two-sided t-test, $\mathrm{p}=0.238, \mathrm{n}=80$ ). 


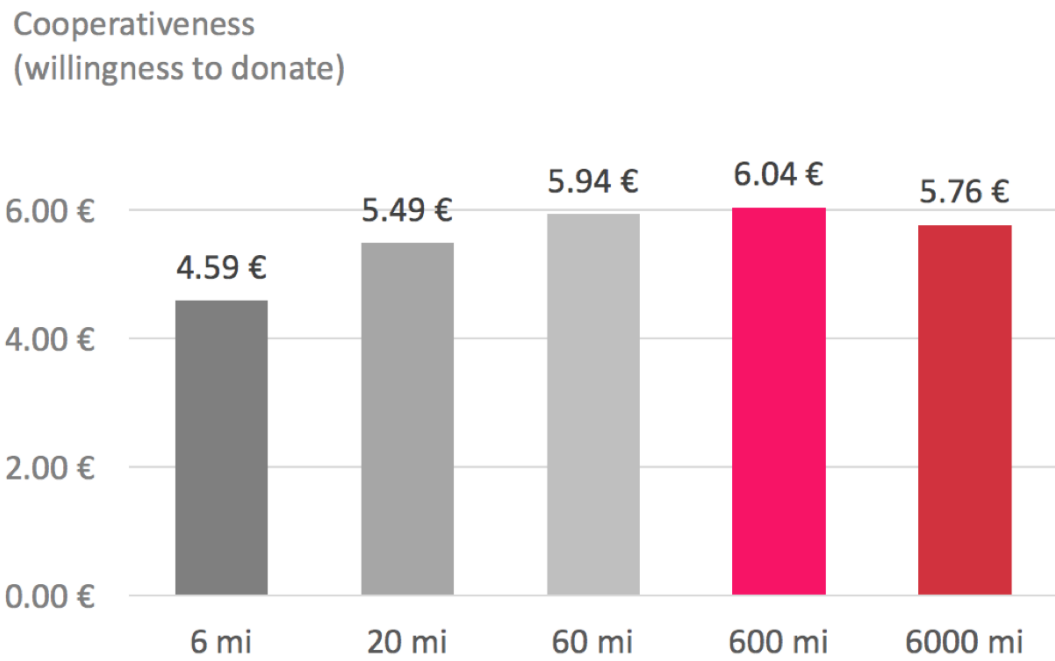

Figure 7: Large distances and cooperativeness. The figure displays mean donations in euro for intermediate and large distances.

Looking at the effects of gender (see Figure 8), we do not find a significant difference. If anything, females tend to donate higher amounts of money than males (overall 6.10 euro for females vs. 5.06 euro for males in intermediate and large distances, two-sided t-test, $\mathrm{p}=0.121, \mathrm{n}=197$ ).

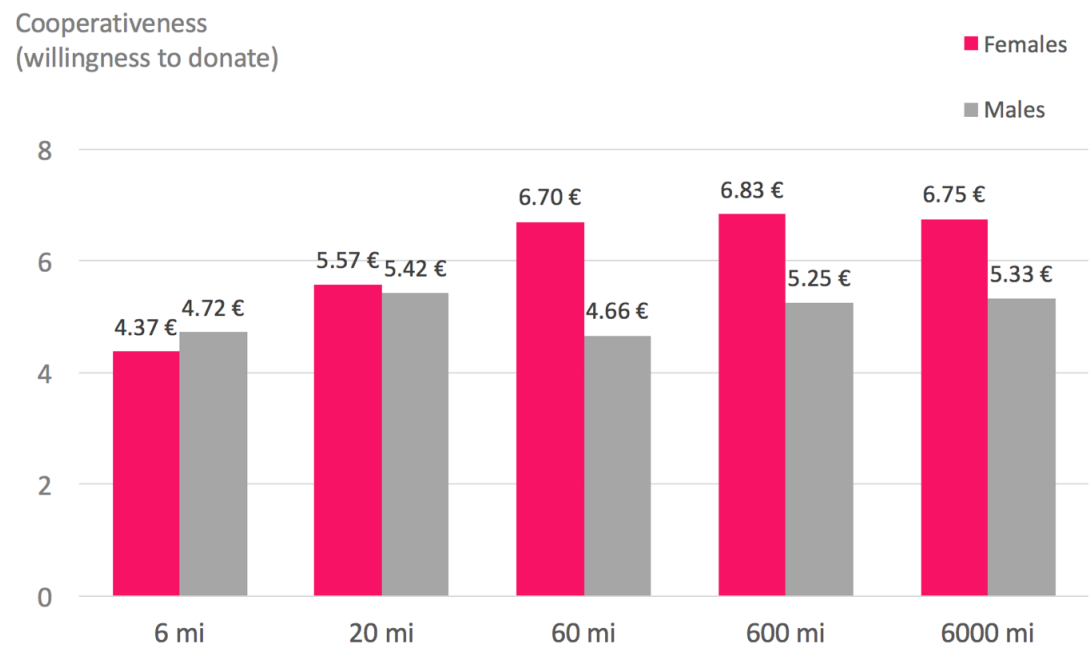

Figure 8: Gender differences in large distances. The figure shows the mean donation in euro for males and females for intermediate and large distances.

Although we do not see a change in behavior for larger distances, partic- 
ipants do feel significantly less responsible towards people in need that are further away (0.2 vs. $6000 \mathrm{mi}$, two-sided t-test, $\mathrm{p}=0.000^{* * *}$, compare Figure 9p. Feelings of responsibility were elicited in an ex-post questionnaire using a 7-point Likert scale.

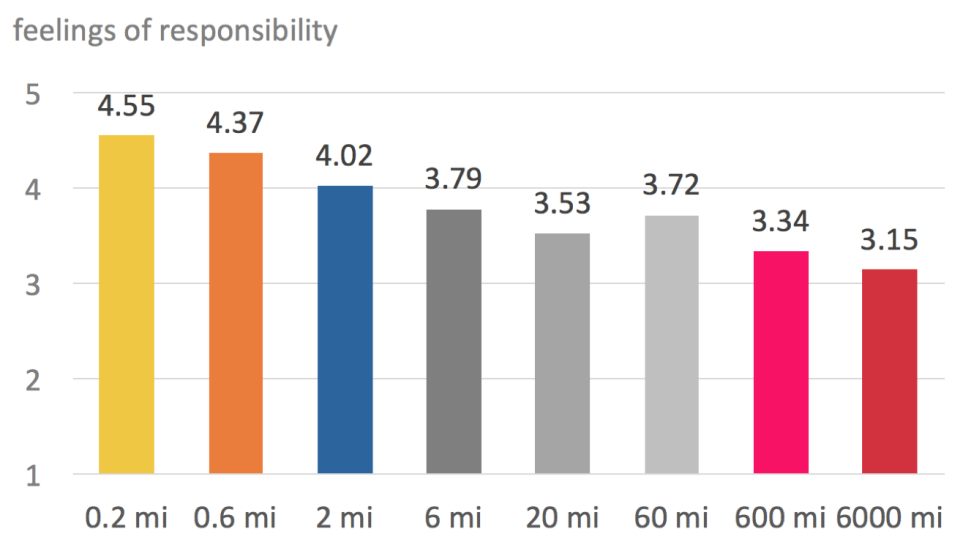

Figure 9: Feelings of responsibility. Participants feel less responsible for people in need that are further away. Feelings of responsibility were elicited on a 7 -point Likert scale.

Furthermore, we analyzed participants arguments and explanations for their decisions. We find that for large distances, participants increasingly refer to a local responsibility towards people in need and to general norms (e.g. sharing equally) or other rules and reference points (e.g. student wages) to justify and explain their behavior. As these salient norms and reference points are relatively generous, this could be a mechanism that increases donations in larger distances. For further analysis of ex-post arguments participants provided, see appendix.

Statistical analysis confirms a structural break in the data, depending on whether destinations vary within Karlsruhe or outside (see Figure 10). Note that we incorporated very far destinations (up to 6,000 miles away). It may well be that participants perceived a donation to such places more urgent than a donation within the comparably rich city of Karlsruhe. We try in the instructions to preempt such impressions by stressing that destinations are economically comparable to Karlsruhe. However, it remains unclear whether we were able to fully suspend these thoughts. 


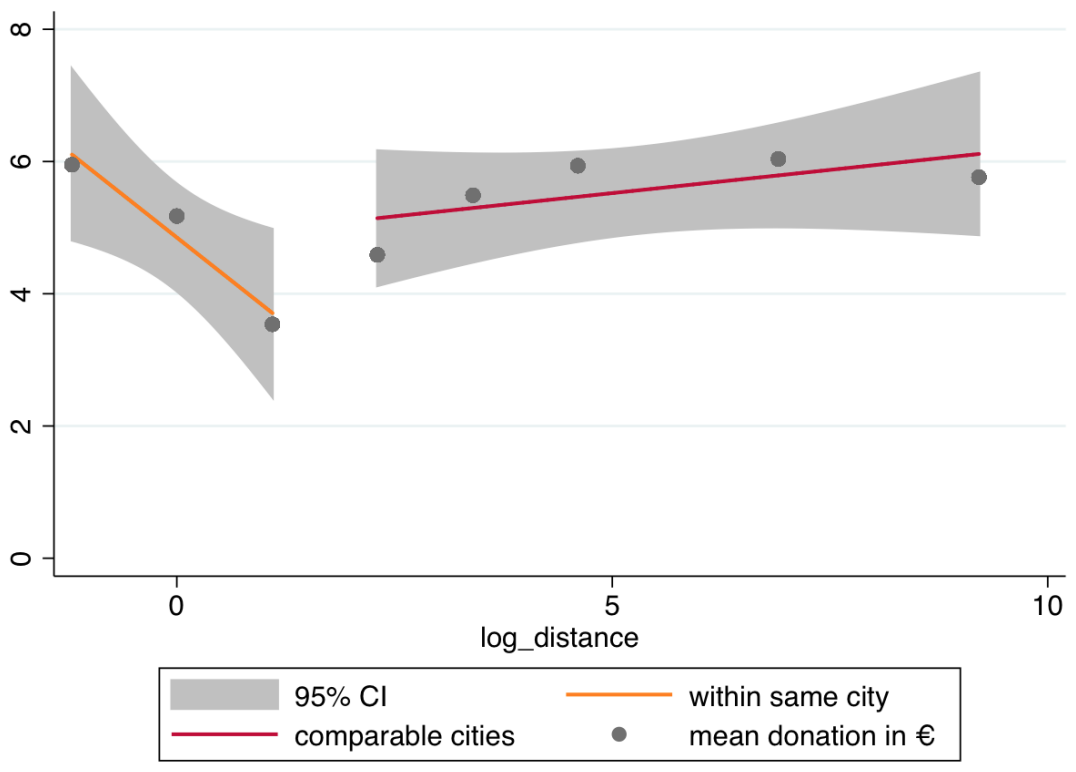

Figure 10: Structural break in donation behavior at 2 miles. We find a structural break in the data for the donation behavior in lower distances within the same city vs. larger distances (Chow test, $\mathrm{p}=0.03^{* *}, \mathrm{n}=320$ ).

\section{Discussion}

Several qualifications need to be made, both, with regard to our field study, and with regard to our laboratory experiment. In the following, we discuss these. Our field study isolates effects of direct exposure and physical proximity on willingness to support non-kins, specifically, refugees. In the following, we discuss three aspects about the study's design: First, we focus on a oneshot situation. Second, we cannot perfectly control for social information in the Exposure treatment. Third, our results on gender stem from an ex post analysis.

We focus on a one-shot situation, that is, we do not measure willingness to provide support over a longer time horizon. Of course, one could imagine that direct exposure may have different effects over time. A first reaction of personal overload or aversion may ultimately change into respect and sympathy. Adaption may take time. Positive experiences could of course further help to overcome initial feelings of overload or even outright aversion. Therefore, our findings should not be taken as a justification for keeping refugees out of sight! For a healthy society, indeed, integration is likely crucial (compare e.g. Brücker (2015)). Nevertheless, understanding instant reactions and behaviors 
is important. Refugee-welcoming countries such as Germany currently face difficulties in keeping the positive attitude towards refugees alive. While still the majority supports the influx of refugees, a substantial fraction of people has taken more aversive positions $\$ 17$. These may be indeed reactions of personal overload that societies need to cope with.

While we handed out the instructions for the different routes in the treatments individually, it may be that participants talked to each other on their way to the study's premises. On their ways, participants did not know what task they would be confronted with in the experiment. Further, there was little reason to discuss the situation of refugees for those participants who took part in the Distance and the Proximity treatment. This may be different for participants in Exposure, who could see the refugee camp on their way. Even though these participants did not know either they would later decide about donating money to refugees from that camp, it may be that general discussions emerged when crossing the camp. When participants arrived at our premises, we did not get any impression that this happened. Yet we cannot control for this as we deliberately chose not to monitor our participants on their way.

Our data display a strong difference between females and males behavior when it comes to causal effects of exposure. For females, exposure works statistically comparably well as proximity alone, fostering cooperativeness compared to the Distance treatment. This is different for males, for whom direct exposure leads to a drastic decline in cooperativeness compared to the Proximity treatment. This data needs to be handled with caution for at least two reasons: First, we did not run a gender-controlled study in the sense that fractions of males and females in the study were not perfectly identical (though close) in the respective treatments. Second, we focus on a student population that certainly does not allow for representative results e.g. with regard to age or educational background. Older people may perceive the situation and exposure differently. Lower education may further lead to different results (compare e.g. Sidanius et al. (1994); Mayda (2006); Schneider (2008)).

Our laboratory experiment isolates effects of physical distance on willingness to support non-kins, specifically, people who get support from charity. Our goal was a) to replicate the findings from the Refugee Paradigm in a different context and b) to investigate the causal impact of (much) larger physical distance. Specifically, in the case of b), it becomes notoriously difficult to keep the impact of a donation to charity comparable. Participants could have more or less trust into charities that operate non-locally. Furthermore, participants could have the impression that the need for money is different in destinations

${ }^{17}$ Compare e.g. The Washington Post $(2016)$ 
physically far away. As Germany is a comparatively rich and non-corrupted country (compare e.g. Transparency International (2017)), and Karlsruhe is a specifically rich city within Germany $(\mathrm{OECD}, 2013)$, participants may feel that their money is more needed in other destinations. Yet they may also trust less that their money reaches people in need if the destination is far away. We tried to preempt these problems by choosing comparable charities, and by stressing in the instructions that destinations were economically comparable to Karlsruhe. But it remains unclear whether we were able to fully suspend these thoughts. In future research, it would be interesting to control those impressions better in order to achieve cleaner measurement of the pure impact of physical distance alone.

\section{Conclusion}

Our data display that varying local, physical distance causally affects human cooperativeness towards non-kins in two different paradigms. These findings are highly relevant for economic models on morally relevant behavior (compare e.g. Ellingsen and Mohlin (2017); Falk and Tirole (2016); Rothenhäusler et al. (2017)) fundamental theoretical work in the social sciences (e.g. Bandura (1999) on moral and social behavior), applied contexts (e.g. Grossman (2009) on military contexts) and evolutionary views on the development of human cooperativeness and morally relevant behavior (e.g. Fessler et al. (2015); Bowles and Gintis (2011)). Our results indicate that physical distance matters significantly in local environments.

In our field study, we focus on the willingness to financially support a local refugee camp as an important aspect of cooperativeness and moral behavior towards genetically unrelated other humans. The support of refugees and migrants and the fostering of cooperativeness in local populations should likely remain of high political and social relevance in the upcoming years. With the climate change, providing support to refugees should likely become an even more pressing topic in future decades (Black et al., 2011). Of course, our field study just provides a snapshot at identifying important mechanisms that trigger human cooperativeness. Yet the findings strongly suggest that effects of physical proximity can be pronounced, and that specific subgroups, e.g. males versus females, may react differently.

Our laboratory experiment also employed donations for charity, yet of course, it was less easy to make sure that destinations of donations remained comparable. We replicate the findings from the Refugee Paradigm. Thus, varying physical distance at local ranges can have significant impact on will- 
ingness to provide support. If distances become large or very large, we see that variations may be of less importance, yet more research would be helpful. Again, gender matters. Overall willingness to donate tends to be less pronounced in males than in females across treatments. 


\section{References}

Andreoni, J. (2006). Philanthropy. In Handbook of the Economics of Giving, Altruism and Reciprocity, Volume 2, pp. 1201 - 1269. Elsevier.

Andreoni, J. (2015). The Economics of Philanthropy and Fundraising. Edward Elgar Pub. Limited.

Andreoni, J., J. M. Rao, and H. Trachtman (2017). Avoiding the Ask: A Field Experiment on Altruism, Empathy, and Charitable Giving. Journal of Political Economy (forthcoming) 125(3), 625-653.

Andreoni, J. and M. Serra-Garcia (2016). Time-Inconsistent Charitable Giving. Working Paper 22824, National Bureau of Economic Research.

Axelrod, Robertand Hamilton, W. D. (1981). The evolution of cooperation. Science 211(274489), 1390-1396.

BAMF Bundesamt für Migration und Flüchtlinge (2016). Aktuelle Zahlen zu Asyl. https://www.bamf.de/SharedDocs/Anlagen/DE/Downloads/ Infothek/Statistik/Asyl/statistik-anlage-teil-4-aktuelle-zahlen-zu-asyl.pdf, last accessed May 2016.

Bandura, A. (1999). Moral disengagement in the perpetration of inhumanities. Personality and Social Psychology Review 3(3), 193-209.

Bekkers, R. and P. Wiepking (2011). A literature review of empirical studies of philanthropy: Eight mechanisms that drive charitable giving. Nonprofit and Voluntary Sector Quarterly 40(5), 924-973.

Bénabou, R. and J. Tirole (2010). Individual and corporate social responsibility. Economica $77(305), 1-19$.

Bernhard, H., U. Fischbacher, and E. Fehr (2006). Parochial Altruism in Humans. Nature 442(7105), 912-915.

Black, R., S. R. Bennett, S. M. Thomas, and J. R. Beddington (2011). Climate Change: Migration as Adaptation. Nature 478(7370), 447-449.

Bowles, S. (2008). Being Human: Conflict: Altruism's Midwife. Nature 456(7220), 326-327.

Bowles, S. and H. Gintis (2004). Persistent Parochialism: Trust and Exclusion in Ethnic Networks. Journal of Economic Behavior 85 Organization 55(1), 1-23. 
Bowles, S. and H. Gintis (2011). A Cooperative Species: Human Reciprocity and its Evolution. Princeton University Press.

Brücker, H. (2015). Aktuelle Berichte - Mehr Chancen als Risiken durch Zuwanderung 01/2015. http://doku.iab.de/aktuell/2015/aktueller_bericht_ 1501.pdf, last accessed November 2016.

Brücker, H., A. Hauptmann, and P. Trübswetter (2015). Aktuelle Berichte Asyl- und Flüchtlingsmigration in die EU und nach Deutschland 8/2015. http://doku.iab.de/aktuell/2015/aktueller_bericht_1508.pdf, last accessed November 2016.

Burnham, T. C. (2003). Engineering Altruism: A Theoretical and Experimental Investigation of Anonymity and Gift Giving. Journal of Economic Behavior \& Organization 50(1), 133-144.

Charness, G. and E. Fehr (2015). From the Lab to the Real World. Science 350 (6260), 512-513.

Clutton-Brock, T. (2009). Cooperation Between Non-kin in Animal Societies. Nature 462 (7269), 51-57.

Croson, R. and U. Gneezy (2009). Gender Differences in Preferences. Journal of Economic Literature 47(2), 448-474.

Cryder, C. and G. Loewenstein (2010). The Critical Link Between Tangibility and Generosity. In The Science of giving: Experimental Approaches to the Study of Charity. Taylor and Francis.

Cryder, C. E., G. Loewenstein, and R. Scheines (2013). The Donor is in the Details. Organizational Behavior and Human Decision Processes 120(1), $15-23$.

DellaVigna, S., J. A. List, U. Malmendier, and G. Rao (2013). The Importance of Being Marginal: Gender Differences in Generosity. The American Economic Review 103(3), 586-590.

Dickert, S. and P. Slovic (2009). Attentional Mechanisms in the Generation of Sympathy. Judgment and Decision Making 4 (4), 297-306.

Die Zeit (2016). Wacht am Biotop - Wie schön, dass plötzlich alle für den Naturschutz sind 14/2016. http://www.zeit.de/2016/14/ fremdenfeindlichkeit-naturschutz, last accessed October 2017. 
Eckel, C., P. J. Grossman, and A. Milano (2007). Is More Information Always Better? An Experimental Study of Charitable Giving and Hurricane Katrina. Southern Economic Journal 74, 388-411.

Ellingsen, T. and E. Mohlin (2017). A Model of Moral Obedience. Working paper, CESifo Area Conferences 2017.

Eurostat (2017). Asylum Statistics. http://ec.europa.eu/eurostat/statisticsexplained/index.php/Asylum_statistics, last accessed April 2017.

Falk, A. and J. J. Heckman (2009). Lab Experiments Are a Major Source of Knowledge in the Social Sciences. Science 326 (5952), 535-538.

Falk, A. and N. Szech (2013). Morals and Markets. Science 340(6133), 707711.

Falk, A. and J. Tirole (2016). Narratives, imperatives and moral reasoning. Working paper, mimeo.

Fehr, E. and U. Fischbacher (2003). The Nature of Human Altruism. Nature 425(6960), 785-791.

Fehr, E. and K. M. Schmidt (1999). A Theory of Fairness, Competition, and Cooperation. Quarterly Journal of Economics 114(3), 817-868.

Ferrière, R. (1998). Evolutionary biology: Help and you shall be helped. Nature 393(6685), 517-519.

Fessler, D. M., H. C. Barrett, M. Kanovsky, S. Stich, C. Holbrook, J. Henrich, A. H. Bolyanatz, M. M. Gervais, M. Gurven, G. Kushnick, A. C. Pisor, C. von Rueden, and S. Laurence (2015). Moral parochialism and contextual contingency across seven societies. Proceedings of the Royal Society B Biological Sciences 282(1813), 20150907.

Frey, B. S. and S. Meier (2004). Social Comparisons and Pro-Social Behavior: Testing "Conditional Cooperation" in a Field Experiment. The American Economic Review 94(5), 1717-1722.

Glazer, A. and K. A. Konrad (1996). A Signaling Explanation for Charity. The American Economic Review 86(4), 1019-1028.

Gneezy, A., U. Gneezy, G. Riener, and L. D. Nelson (2012). Pay-what-youwant, identity, and self-signaling in markets. Proceedings of the National Academy of Sciences 109(19), 7236-7240. 
Gray, J. G. (1999). The Warriors: Reflections on Men in Battle. University of Nebraska Press.

Greiner, B. (2015). Subject Pool Recruitment Procedures: Organizing Experiments With ORSEE. Journal of the Economic Science Association 1(1), $114-125$.

Grossman, D. (2009). On Killing: The Psychological Cost of Learning to Kill in War an Society. Little Brown, revised edition.

Henrich, J., R. Boyd, S. Bowles, C. Camerer, E. Fehr, H. Gintis, and R. McElreath (2001). In Search of Homo Economicus: Behavioral Experiments in 15 Small-Scale Societies. The American Economic Review 91(2), 73-78.

Hoffman, E., K. A. McCabe, and V. L. Smith (1998). Behavioral Foundations of Reciprocity: Experimental Economics and Evolutionary Psychology. Economic Inquiry 36(3), 335-352.

Isen, A. M. and A. Noonberg (1979). The effect of photographs of the handicapped on donation to charity: When a thousand words may be too much. Journal of Applied Social Psychology 9(5), 426-431.

Jones, T. M. (1991). Ethical decision making by individuals in organizations: An issue-contingent model. Academy of Management Review 16(2), 366395.

Kirchler, M., J. Huber, M. Stefan, and M. Sutter (2015). Market Design and Moral Behavior. Management Science 62(9), 2615-2625.

Krupka, E. and R. A. Weber (2009). The focusing and informational effects of norms on pro-social behavior. Journal of Economic Psychology 30(3), $307-320$.

Lee, B. A. and C. R. Farrell (2003). Buddy, Can You Spare a Dime? Homelessness, Panhandling, and the Public. Urban Affairs Review 38(3), 299-324.

Liberman, N., Y. Trope, and E. Stephan (2007). Psychological Distance. In Social Psychology: Handbook of Basic Principles, pp. 353-383. The Guilford Press, second edition.

Loewenstein, Georgeand Small, D. A. (2003). Helping a Victim or Helping the Victim: Altruism and Identifiability. Journal of Risk and uncertainty 26(1), $5-16$. 
Mayda, A. M. (2006). Who is against immigration? A cross-country investigation of individual attitudes toward immigrants. The Review of Economics and Statistics 88(3), 510-530.

McAndrew, F. T. and M. A. Milenkovic (2002). Of Tabloids and Family Secrets: The Evolutionary Psychology of Gossip. Journal of Applied Social Psychology 32(5), 1064-1082.

Mead, M. (2002). Cooperation and Competition Among Primitive Peoples. Transaction Publishers, second edition.

Meier, S. (2006). A survey of economic theories and field evidence on pro-social behavior. Working Paper 06-6, FRB Boston.

Milgram, S. (1974). Obedience to Authority: An Experimental View. Harper and Row.

Navarrete, C. D., M. M. McDonald, L. E. Molina, and J. Sidanius (2010). Prejudice at the Nexus of Race and Gender: An Outgroup Male Target Hypothesis. Journal of Personality and Social Psychology 98(6), 933-945.

Nisbett, R. E. and L. Ross (1980). Human Inference: Strategies and Shortcomings of Social Judgment. Prentice Hall.

Nowak, M. A. and K. Sigmund (2005). Evolution of Indirect Reciprocity. Nature 437(7063), 1291-1298.

OECD (2013). Stat: Metropolitan areas: GDP from cities. https://stats.oecd. org/Index.aspx?DataSetCode=CITIES, last accessed July 2017.

Pratto, F., J. Sidanius, L. M. Stallworth, and B. F. Malle (1994). Social Dominance Orientation: A Personality Variable Predicting Social and Political Attitudes. Journal of personality and social psychology 67(4), 741-763.

Rabin, M. (1993). Incorporating Fairness into Game Theory and Economics. The American Economic Review 83, 1281-1302.

Rigdon, M., K. Ishii, M. Watabe, and S. Kitayama (2009). Minimal Social Cues in the Dictator Game. Journal of Economic Psychology 30(3), 358367.

Rothenhäusler, D., N. Schweizer, and N. Szech (2017). Guilt in Voting and Public Good Games. European Economic Review, online. 
Schneider, S. L. (2008). Anti-Immigrant Attitudes in Europe: Outgroup Size and Perceived Ethnic Threat. European Sociological Review 24(1), 53-67.

Science (2005). Special Issue 1 July 2005 (125th Anniversary): The Top 25 Questions. http://www.sciencemag.org/site/feature/misc/webfeat/125th, last accessed November 2016.

Shang, J. and R. Croson (2009). A Field Experiment in Charitable Contribution: The Impact of Social Information on the Voluntary Provision of Public Goods. The Economic Journal 119(540), 1422-1439.

Sidanius, J., B. Cling, and F. Pratto (1991). Ranking and Linking as a Function of Sex and Gender Role Attitudes. Journal of Social Issues 47(3), 131-149.

Sidanius, J., F. Pratto, and L. Bobo (1994). Social Dominance Orientation and the Political Psychology of Gender: A Case of Invariance? Journal of Personality and Social Psychology 67(6), 998-1011.

Small, D. A., G. Loewenstein, and P. Slovic (2007). Sympathy and callousness: The impact of deliberative thought on donations to identifiable and statistical victims. Organizational Behavior and Human Decision Processes 102(2), 143-153.

Smith, C. E., P. R. Blake, and P. L. Harris (2013, 03). I Should but I Wont: Why Young Children Endorse Norms of Fair Sharing but Do Not Follow Them. PLOS ONE 8(3), 1-11.

Soetevent, A. R. (2005). Anonymity in giving in a natural context - a field experiment in 30 churches. Journal of Public Economics 89(11), 2301-2323.

Süddeutsche Zeitung (2014). Ich habe nichts gegen Flüchtlinge, aber - Proteste besorgter Anwohner. http://www.sueddeutsche.de/politik/protestebesorgter-anwohner-ich-habe-nichts-gegen-fluechtlinge-aber--1.2243945, last accessed October 2017.

The Economist (2005). Germanys refugee anniversary: Assimilation report. 03 September 2016. http://www.economist.com/news/europe/21706329year-after-angela-merkel-welcomed-migrants-two-syrians-differ-whetherintegration-can, last accessed November 2016.

The Washington Post (2016). World Views: Germany welcomed more than 1 million refugees in 2015 - Now, the country is searching for 
its soul. https://www.washingtonpost.com/news/worldviews/wp/2016/ 05/04/germany-welcomed-more-than-1-million-refugees-in-2015-now-thecountry-is-searching-for-its-soul, last accessed November 2016.

Transparency International (2017). Corruption Perceptions Index 2016. https://www.transparency.org/whatwedo/publication/ corruption_perceptions_index_2016, last accessed July 2017.

Trivers, R. L. (1971). The Evolution of Reciprocal Altruism. The Quarterly Review of Biology 46(1), 35-57.

Trussel, J. M. and L. M. Parsons (2007). Financial Reporting Factors Affecting Donations to Charitable Organizations. Advances in Accounting 23, 263285.

Uslaner, E. M. (2004). Trust and Corruption. In The New Institutional Economics of Corruption, pp. 76-92. Routledge London.

Van Vugt, M. and P. A. Van Lange (2006). The Altruism Puzzle: Psychological Adaptations for Prosocial Behavior. In Evolution and Social Psychology, pp. 237-261. Psychosocial Press, Madison, CT.

Vesterlund, L. (2006). Why Do People Give? In The Nonprofit Sector: A research Handbook, pp. 568-587. Yale University Press.

Vugt, M. v., D. D. Cremer, and D. P. Janssen (2007). Gender Differences in Cooperation and Competition: The Male-Warrior Hypothesis. Psychological science 18(1), 19-23. 


\section{Appendix}

\subsection{The Refugee Paradigm}

In the following section of the appendix, we provide additional findings of the Refugee Paradigm (see section 5.1.1). This includes additional findings concerning personal differences, the analysis of ex-post arguments of the participants as well as a robustness check of our results. Section 5.1 .2 provides further information concerning the experimental procedures and implementation of the Refugee Paradigm. The translated instructions can be found in section 5.1.3.

\subsubsection{Additional Findings and Discussion}

Sharers feel good. We find a highly significant difference in happiness measures (5-point-scale), both right after the decision and at the end of the study $(\mathrm{p}<0.01$, two-sided t test, respectively, $\mathrm{n}=155$, see Figure 11).

The sharing decision is in line with general personality traits. As expected, agreeableness, openness, compassion and attitudes against vs. in favor of military intervention of the refugee crisis correlate significantly with cooperativeness towards refugees in the camp as depicted in Figure 12. Openness and agreeableness have been associated with lower prejudice, more positive attitudes towards immigrants (Ekehammar and Akrami, 2003; Akrami et al., 2010; Gallego and Pardos-Prado, 2014) as well as prosocial motivation (Graziano et al., 2007) and altruistic behavior towards strangers (Oda et al., 2014). We elicited openness and agreeableness according to the well-established Big Five inventory (Allport and Odbert, 1936, Satow, 2012).

Cognitively skilled participants are more likely to behave cooperatively and opt for sharing $(\mathrm{p}<0.01$, two-sided t-test, $\mathrm{n}=155)$. We elicit cognitive ability using a 12-item questionnaire for crystallized intelligence (Schipolowski et al., 2013). We used matrices from Ravens Advanced Progressive Matrices Plus to elicit fluid intelligence as the second important factor in general intelligence (Cattell, 1971).

More impulsive participants tend to share less likely $(\mathrm{p}<0.1$, logistic regression, $\mathrm{n}=154$ ) which further supports that sharers took a reflected decision. We elicited impulsiveness using a three-item inventory based on Whiteside and Lynam (2001), also compare Kovaleva et al. (2012).

Participants in favor of non-redistributive parties share less likely. When asked for which party participants would vote in an upcoming election, 


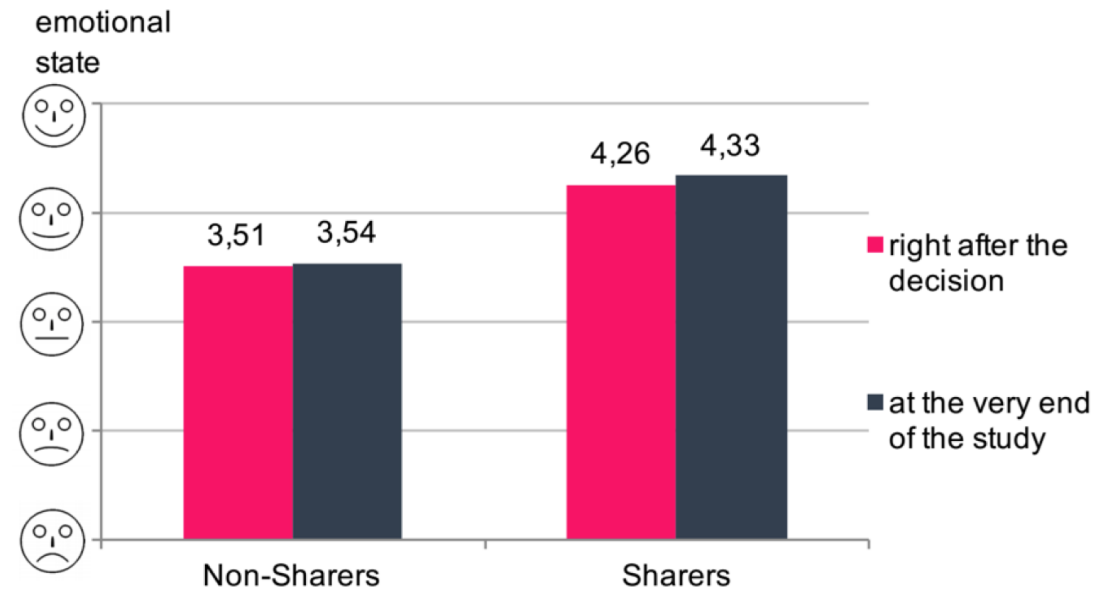

Figure 11: Emotional state of sharers vs. non-sharers. Sharers feel significantly better about their decision, both right after the decision as well as at the end of the study $(\mathrm{p}<0.01$, two-sided t-test, respectively, $\mathrm{n}=155)$.

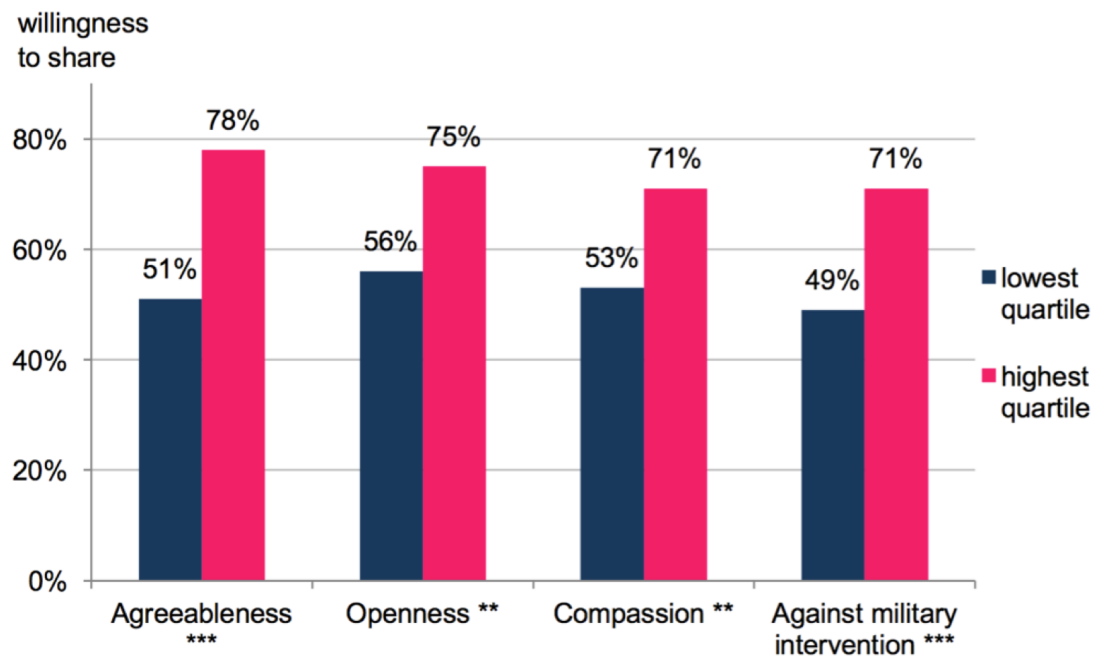

Figure 12: Personality traits and the willingness to share, comparing highest versus lowest quartiles, respectively. As expected, agreeableness $(\mathrm{p}<0.01$, one-sided t-test, $\mathrm{n}=84)$, openness $(\mathrm{p}<0.05$, one-sided t-test, $\mathrm{n}=87)$, compassion $(\mathrm{p}<0.05$, one-sided t-test, $\mathrm{n}=89)$ and attitudes against military intervention regarding the refugee crisis $(\mathrm{p}<0.01$, one-sided t-test, $\mathrm{n}=127)$ correlate with cooperativeness towards refugees in the camp. 
we find the tendency that participants in favor of less redistributive parties tend to share less likely (see Figure 13). Participants in favor of the nonredistributive parties FDP and CSU have a significantly lower willingness to share $\left(42 \%\right.$ as opposed to $69 \%, \mathrm{p}<0.05$, two-sided t-test, $\left.\mathrm{n}=12 \mathrm{q}^{18}\right)$.

Own Financial Situation as an Excuse? In an ex post questionnaire, we ask participants about the reasons for their decision. Financial justifications for the sharing decision are less frequent in Proximity and especially in Exposure (see Figure 14). The decrease of financial arguments is significant in Distance vs. Exposure $(\mathrm{p}<0.01$, two-sided t-test, $\mathrm{n}=100)$ as well as in Proximity vs. Exposure $(\mathrm{p}<0.05$, two-sided t-test. $\mathrm{n}=106)$.

There is no significant difference in income or in the evaluation of ones financial situation between treatments. Interestingly, non-sharers report more financial worries in an ex post questionnaire $(\mathrm{p}<0.01$, two-sided t-test over all treatments, $n=155)$, although their actual income is not significantly different from that of sharers $(\mathrm{p}=0.23$, two-sided t-test over all treatments, $\mathrm{n}=155)$. Maybe, participants were consciously or subconsciously using their own financial situation as an excuse for deciding to keep the money instead of sharing it. Potentially, they find it less credible to themselves (or others) to argue with financial worries when the current situation of refugees and migrants is physically closer and thus more salient.

Proximity changes the ways of reasoning and justification. We find that non-sharers reasons for their decision tend to change in its nature when proximity is increased (compare Figure 15). Concrete reasons like participants own financial needs, or critical views of donations in general are less frequent in Exposure. In contrast, rather abstract and malleable arguments (like preferring to give other kind of support to maybe other people at another time, or some feeling of lack of clarity in the donation purpose) increase in Proximity. Participants emphasize all kinds of prior or hypothetical prosocial acts and substitutes to the sharing decision to legitimate their decision not to share. Furthermore, non-sharers tend to report to be more actively involved in volunteer work than sharers, with a significant difference in the Exposure treatment $(\mathrm{p}<0.01$, two-sided t-test, $\mathrm{n}=51)$. Maybe, general and selfishness-driven reasons seem less appropriate in a situation that is close in Proximity and becomes even more specific in Exposure. Possibly, the decision not to share is perceived more negatively when physically close and exposed (Proximity and Exposure)

\footnotetext{
${ }^{18}$ Some participants also stated that they would not vote or they would give an invalid vote. Very few participants would vote other parties including the relatively new parties AfD $(n=1)$ and Die PARTEI $(n=4)$.
} 


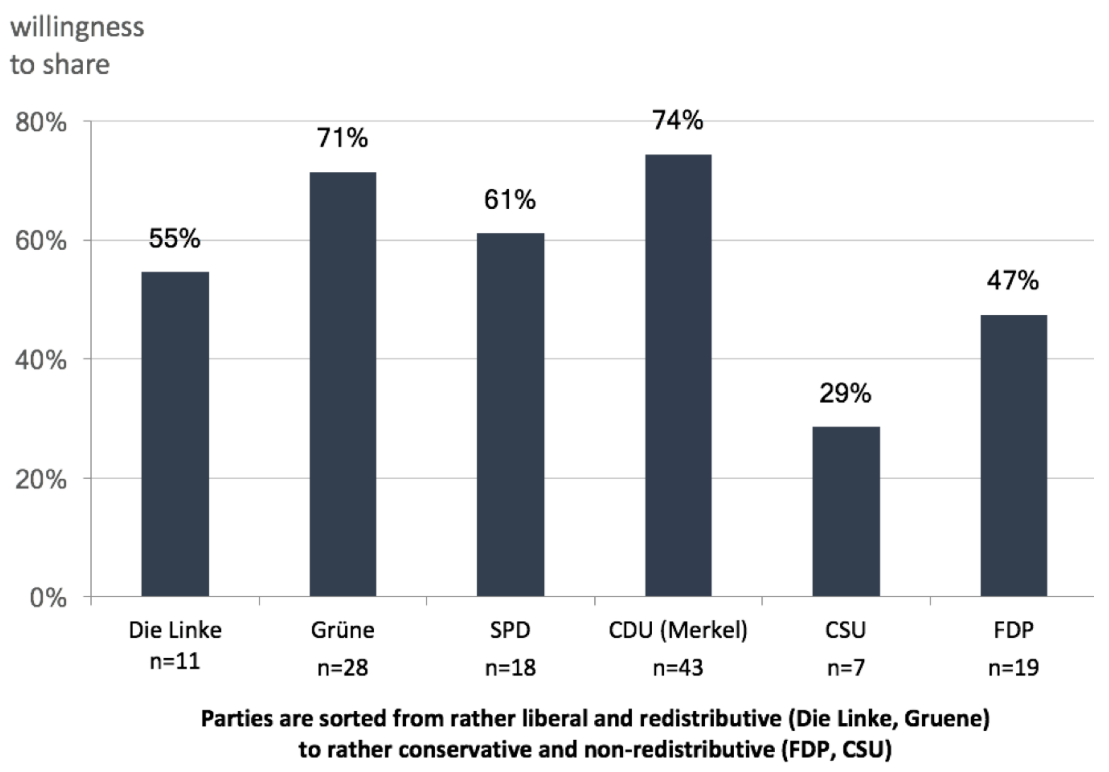

Figure 13: Political Orientation and Cooperativeness. Favoring redistributive parties is correlated with a higher willingness to cooperate and sharing ( $69 \%$ vs. $42 \%, \mathrm{p}<0.05$, two-sided t-test, $\mathrm{n}=126$ ).

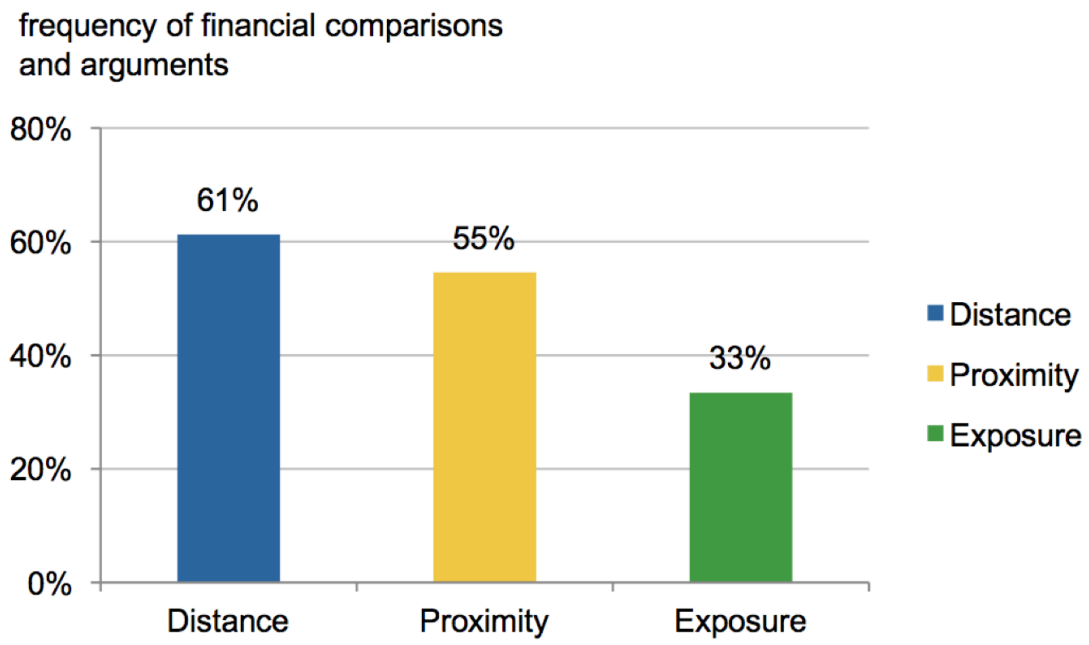

Figure 14: Frequency of financial arguments in the Distance, Proximity and Exposure treatments. Financial arguments are less frequently used in Proximity and especially in Exposure (55\% in Proximity and 33\% in Exposure compared to $61 \%$ in Distance, $\mathrm{n}=155)$. 
resulting in stronger urges to compensate in order to keep a positive self-image (compare e.g. Fessler et al. (2015); Festinger (1962)).

Did contradictory expectations lead to personal overload? In addition to the changes in reasoning, we find that participants in Exposure tend to feel less informed (two-sided t-test Proximity vs. Exposure, $\mathrm{p}=0.11, \mathrm{n}=105$ ). We also find that with regard to political interest, the results are mixed. Higher political interest is correlated with a higher willingness to share in Distance $(\mathrm{p}<0.10$, two-sided t-test, $\mathrm{n}=49)$. But we also find that, in Exposure, political interest is correlated with a lower willingness to share $(\mathrm{p}<0.05$, two-sided $\mathrm{t}$ test, $\mathrm{n}=51$ ). This might reflect contradictions between the participants expectations and their newly gained observations at the refugee camp. Maybe, the new conflicting information with participants expectations and beliefs induced a personal overload-effect that lead to decreased sharing behavior. Moral information overload has been shown to affect donations negatively (Kajonius, 2014). Among sharers, the four most common reasons were financial arguments, altruism, no perceived loss (the payout of the experiment was perceived as a bonus in participants budgets) and the convenience of this opportunity to donate (compare Figure 16).

Treatment effects are robust. To further investigate correlations between cooperativeness and personal characteristics and to check our results for robustness, we conduct a logistic regression. Table 4 in the appendix reports the results of this logistic regression with the sharing decision as the (binary) dependent variable.

First, we focus on the correlation between overall cooperativeness and personal characteristics (compare column (1)-(3), data is pooled over all treatments). We start with the two personality measures agreeableness and openness that have been associated with higher prosociality (compare e.g. Graziano et al., 2007) and higher altruistic behavior towards strangers (compare e.g. Oda et al. (2014)). In line with the literature, we find that participants with higher levels of agreeableness and openness are more likely to share (compare column (1)). Furthermore, we consider personal differences that have been discussed to be associated with moral behavior (compare e.g. Loe et al. (2000); OFallon and Butterfield (2005); Millet and Dewitte (2007)): gender and IQ (compare column (2)). Gender does not always lead to significant differences in moral behavior, but if so, females typically tend to be more moral. Further, a higher IQ and education has been found to correlate with more moral decisions. In line with the latter, we find that more intelligent participants are more likely to opt for sharing. We furthermore find that gender plays 


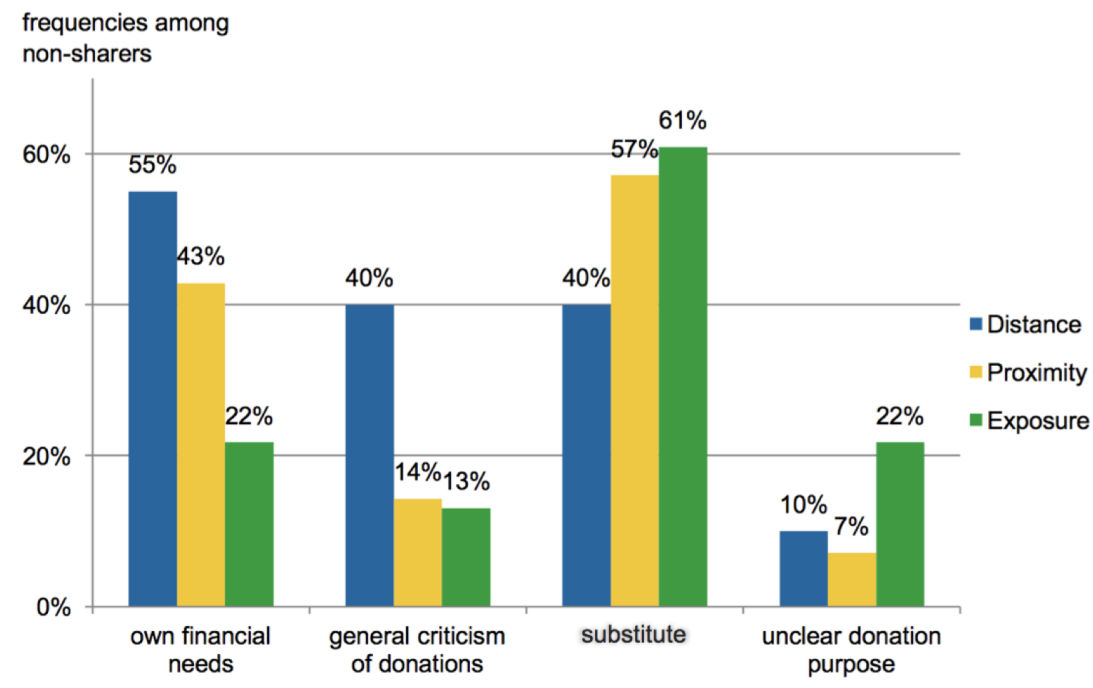

Figure 15: Most frequent reasons for not sharing. Multiple answers and reasons were possible. There was a total of $n=57$ non-sharers.

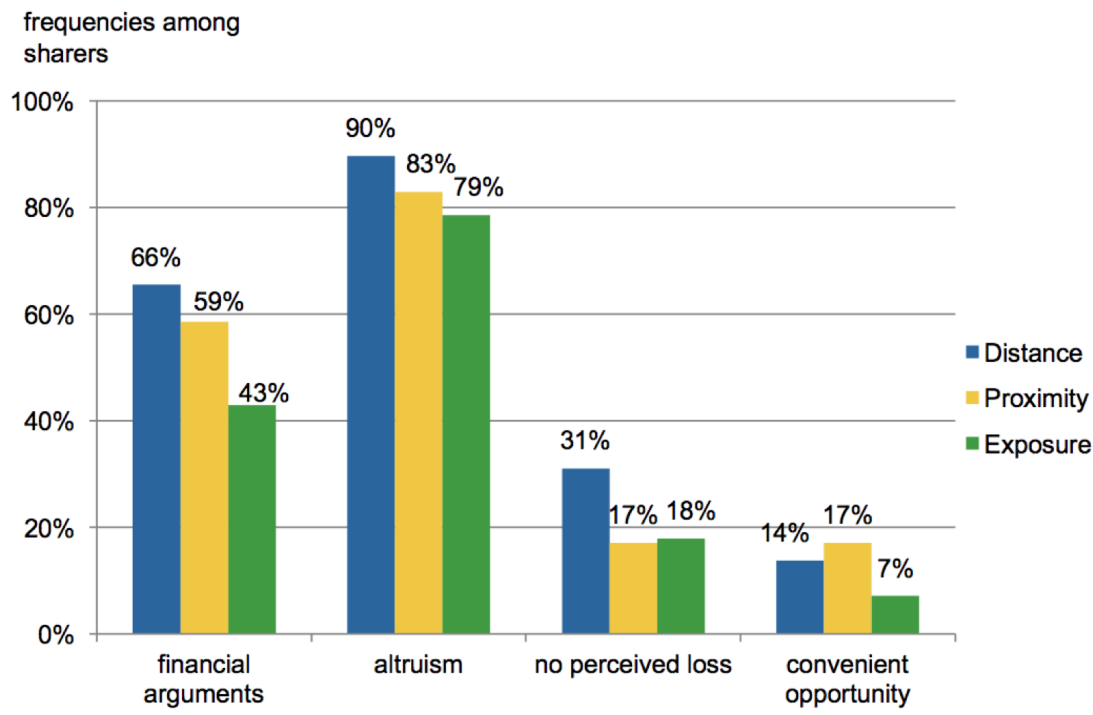

Figure 16: Most frequent reasons for sharing. Multiple answers and reasons were possible. There was a total of $n=98$ sharers. 
no significant role in the pooled data. Controlling for social attitudes and political orientation (compare column (3)), the data display a positive correlation between cooperativeness and feelings of compassion towards refugees and a negative correlation between cooperativeness and supporting military intervention in the refugee crisis. We do not find a significant difference between participants with different political orientation (voting for more vs. less redistributive parties).

To check our main findings for robustness, we introduce treatment variables for Proximity and Exposure and use the control variables for personal characteristics (compare column (4)). Again, the data reveal a significantly higher cooperativeness for the Proximity treatment. This demonstrates the robustness of the effect. The findings are also robust to potential differences in feeling informed about the situation of the refugees: Using further control variables for informational bias, exposure to the refugee camp prior to the study and the impact of recent politically important events in Europe (compare column (5)), we do not find evidence that these factors influenced or distorted the results.

Last, we test the results regarding the interaction of gender and exposure for robustness (compare column (6)). Including the respective interaction terms, the regression confirms that males and females react significantly different in the Exposure treatment: Males are less willing to share than females. The regression results thus confirm that our main findings are robust to the introduction of multiple controls. 


\begin{tabular}{|c|c|c|c|c|c|c|}
\hline & \multicolumn{3}{|c|}{$\begin{array}{c}\text { Personality and overall } \\
\text { cooperativeness } \\
\text { (pooled data over all treatments) }\end{array}$} & \multicolumn{2}{|c|}{$\begin{array}{l}\text { Robustness of } \\
\text { treatment effects }\end{array}$} & \multirow{2}{*}{$\begin{array}{c}\begin{array}{c}\text { Gender } \\
\text { Interaction }\end{array} \\
(6)\end{array}$} \\
\hline & (1) & $(2)$ & $(3)$ & $(4)$ & $(5)$ & \\
\hline proximity & & & & $\begin{array}{l}1.368^{* * *} \\
{[0.529]}\end{array}$ & $\begin{array}{l}1.271^{\star *} \\
{[0.544]}\end{array}$ & $\begin{array}{l}1.699^{\star} \\
{[0.878]}\end{array}$ \\
\hline exposure & & & & $\begin{array}{l}-0.107 \\
{[0.485]}\end{array}$ & $\begin{array}{l}-0.254 \\
{[0.504]} \\
\end{array}$ & $\begin{array}{l}1.003 \\
{[0.820]} \\
\end{array}$ \\
\hline agreeable & $\begin{array}{l}0.939^{\star \star} \\
{[0.426]}\end{array}$ & $\begin{array}{l}1.089^{\star \star} \\
{[0.453]}\end{array}$ & $\begin{array}{l}1.210^{\star \star *} \\
{[0.490]}\end{array}$ & $\begin{array}{l}1.191^{\star \star} \\
{[0.509]}\end{array}$ & $\begin{array}{l}1.302^{\star *} \\
{[0.536]}\end{array}$ & $\begin{array}{l}1.186^{\star *} \\
{[0.549]}\end{array}$ \\
\hline open & $\begin{array}{l}0.739^{\star} \\
{[0.404]}\end{array}$ & $\begin{array}{l}0.574 \\
{[0.421]} \\
\end{array}$ & $\begin{array}{l}0.221 \\
{[0.461]} \\
\end{array}$ & $\begin{array}{l}0.127 \\
{[0.477]} \\
\end{array}$ & $\begin{array}{l}0.039 \\
{[0.490]}\end{array}$ & $\begin{array}{l}0.037 \\
{[0.510]} \\
\end{array}$ \\
\hline iqc & & $\begin{array}{l}0.246^{* * *} \\
{[0.092]}\end{array}$ & $\begin{array}{l}0.305^{\star \star \star} \\
{[0.100]}\end{array}$ & $\begin{array}{l}0.359^{\star * \star} \\
{[0.108]}\end{array}$ & $\begin{array}{l}0.362^{* k *} \\
{[0.113]}\end{array}$ & $\begin{array}{l}0.365^{\star \star \star} \\
{[0.113]}\end{array}$ \\
\hline male & & $\begin{array}{l}-0.442 \\
{[0.378]}\end{array}$ & $\begin{array}{l}0.045 \\
{[0.439]}\end{array}$ & $\begin{array}{l}0.043 \\
{[0.461]}\end{array}$ & $\begin{array}{l}0.036 \\
{[0.479]}\end{array}$ & $\begin{array}{l}0.997 \\
{[0.796]}\end{array}$ \\
\hline prox_male & & & & & & $\begin{array}{l}-0.628 \\
{[1.084]}\end{array}$ \\
\hline exp_male & & & & & & $\begin{array}{l}-2.076^{\star *} \\
{[1.059]}\end{array}$ \\
\hline compassion & & & $\begin{array}{l}0.444^{* * *} \\
{[0.166]}\end{array}$ & $\begin{array}{l}0.514^{* * *} \\
{[0.174]}\end{array}$ & $\begin{array}{l}0.688^{* * *} \\
{[0.214]}\end{array}$ & $\begin{array}{l}0.627^{\star \star * *} \\
{[0.214]}\end{array}$ \\
\hline military & & & $\begin{array}{l}-0.304^{\star *} \\
{[0.125]}\end{array}$ & $\begin{array}{l}-0.352^{\star * \star} \\
{[0.133]}\end{array}$ & $\begin{array}{l}-0.346^{\star \star} \\
{[0.139]}\end{array}$ & $\begin{array}{l}-0.384^{\star * *} \\
{[0.141]}\end{array}$ \\
\hline less_redistributive & & & $\begin{array}{l}-0.786 \\
{[0.517]}\end{array}$ & $\begin{array}{l}-1.026^{*} \\
{[0.553]}\end{array}$ & $\begin{array}{l}-0.953^{*} \\
{[0.560]}\end{array}$ & $\begin{array}{l}-0.851 \\
{[0.576]}\end{array}$ \\
\hline informed & & & & & $\begin{array}{l}-0.139 \\
{[0.154]}\end{array}$ & $\begin{array}{l}-0.138 \\
{[0.154]}\end{array}$ \\
\hline exposurecampbefore & & & & & $\begin{array}{l}0.034 \\
{[0.519]}\end{array}$ & $\begin{array}{l}0.077 \\
{[0.536]}\end{array}$ \\
\hline parisinfluence & & & & & $\begin{array}{l}-0.029 \\
{[0.139]}\end{array}$ & $\begin{array}{l}0.106 \\
{[0.301]}\end{array}$ \\
\hline Constant & $\begin{array}{l}0.129 \\
{[0.214]}\end{array}$ & $\begin{array}{l}-1.650^{\star \star} \\
{[0.762]} \\
\end{array}$ & $\begin{array}{l}-3.293^{\star \star} \\
{[1.320]} \\
\end{array}$ & $\begin{array}{l}-4.247^{\star * \star} \\
{[1.471]}\end{array}$ & $\begin{array}{l}-4.504^{\star \star \star} \\
{[1.664]}\end{array}$ & $\begin{array}{l}-4.714^{\star \star \star} \\
{[1.614]}\end{array}$ \\
\hline Pseudo R2 & 0.045 & 0.083 & 0.194 & 0.246 & 0.259 & 0.280 \\
\hline Log likelihood & -97.397 & -93.500 & -81.801 & -76.494 & -73.475 & -71.346 \\
\hline observations & 155 & 155 & 154 & 154 & 150 & 150 \\
\hline
\end{tabular}

Table 4: Validity and robustness check. The table displays logistic regression coefficients (sharing decision as dependent variable, binary), standard errors in brackets. $* * * / * * / *$ indicate significance on a $1-/ 5-/ 10$-percent level respectively.

\subsubsection{Procedures}

Our controlled, randomized economic field study took place on November 16 and November 17 in 2015, at and around the campuses of a German university, 
the Karlsruhe Institute of Technology (KIT). All participants are invited to the meeting point of the study. They register, and are then individually and one by one handed out maps and route descriptions that inform them to go to different places according to the respective treatment (compare appendix section 5.2.3). They do not receive further instructions or information about the subsequent study. All participants follow routes that lead them to the respective premises in about 15 minutes walking time (compare Figure 1). Participants are guided to salient points at the respective campus (gate areas) and then follow paper signs for the last meters. This ensures that participants can not deviate from the intended routes at the end. Thus, accidental exposure to the camp in Proximity or the lack of it in Exposure can be prevented. The different routes are chosen such that they are as comparable in length and pathway features as possible (e.g. number of recognizable features and major turns, amount of green and woody areas on the way, streets and bike lanes, starting and ending on a campus with university buildings, plausibility) ${ }^{19}$. Treatment and respective route are determined and rechecked right before each session. In an ex post questionnaire, we control for means of transportation and deviations from the provided route (only 4 out of all 155 participants state that they partly deviated from the provided routes).

A large refugee camp is located close to the premises of the treatments Proximity and Exposure (about 0.2 miles away). This camp is only visible coming from one specific direction. Participants in the Exposure treatment follow a route that partly goes alongside the camp, such that seeing the camp is basically inevitable. 47 out of all 51 participants (92\%) in Exposure answered in the ex post questionnaire that they had seen the camp on their way. Participants in the other treatments do not see the camp following their routes ${ }^{20}$ In an ex post questionnaire, we control for exposure towards the camp prior to this study and exposure towards the camp and refugees on the way to the study. The vast majority of participants $(82 \%)$ has not seen the camp before.

When participants arrive at the respective buildings on Campus East and Campus South, they are individually and silently seated in cardboard cubicles

\footnotetext{
${ }^{19}$ As this is a field study in a real environment, there are of course some control limitations. However, we have no reason to believe that our data has major flaws. Routes have been checked before each elicitation, workers at the refugee camp reported regular activity in the camp and we did not receive any complaints or reports of extraordinary incidents.

${ }^{20}$ In Proximity, 5 participants claim to have seen the camp. Given the routes and signs they must have followed on Campus East to arrive at the study's premises, this is highly unlikely. Maybe, participants mistook other buildings for the camp, knowing that the camp was physically close (0.2 miles) when asked whether they had seen it.
} 
and handed out the instructions for the main decision (compare section 5.1.3). It is only then that they become confronted with the decision to share money with refugees: They can allocate 15 euro between themselves and refugees from the camp. ${ }^{21}$ The choice is binary, such that participants can either keep the 15 euro entirely to themselves, or keep half of the money, i.e. 7.50 euro, and donate the other half to refugees. It is important to incentivize this decision. If there was no real money involved, it would be cheap for participants to claim they would like to share money with refugees. Participants in all treatments know that the money donated benefits refugees at the local camp. In Distance, participants know that this camp is about 2 miles away from where they decide. In Proximity and Exposure, participants know that the camp is 0.2 miles away. Physical distance to the refugee camp is thus about ten times higher in Distance compared the other two treatments, Proximity and Exposure. In addition, in Exposure, participants have seen the camp on their way, in contrast to the other two treatments. After the main decision, all participants take part in a social-demographic questionnaire. Participants in all treatments know that their decisions and payments are anonymous. At the end of each session, payments are submitted in sealed envelopes and neither the present experimenters nor the participants know the decisions or payments of others.

We used the software ORSEE to recruit participants for this study Greiner, 2015). A total of 155 participants (59\% males) took part in the study. There was no drop-out between registering at the meeting point and ending up at the assigned destination. Overall duration per session was about 90 minutes. Participants knew beforehand that they received 5 euro as a compensation for coming to the meeting point, a slightly remote lecture hall (called "Hörsaal am Fasanengarten") of the KIT. After registering at the meeting point, they followed different routes to the study's respective premises, according to treatment. Only participants in the Exposure treatment followed a route next to the local refugee camp.

Figure 17 shows the camp right before participants in the Exposure treatment were elicited. We see mostly young males playing soccer in front of the camp. To the left, some refugees dry their clothes outside. Some refugees sit alone on benches or in other slightly remote locations, often in seemingly reflective positions. To the best of our knowledge, there were no exceptional

\footnotetext{
${ }^{21}$ Participants knew that these 15 euro came in addition to 5 euro for coming to the meeting point (show-up fee).
} 
incidents or events around or inside the camp on November 16 and November 17 in 2015. Yet of course, the exact impression and perception of the camp might differ between participants.
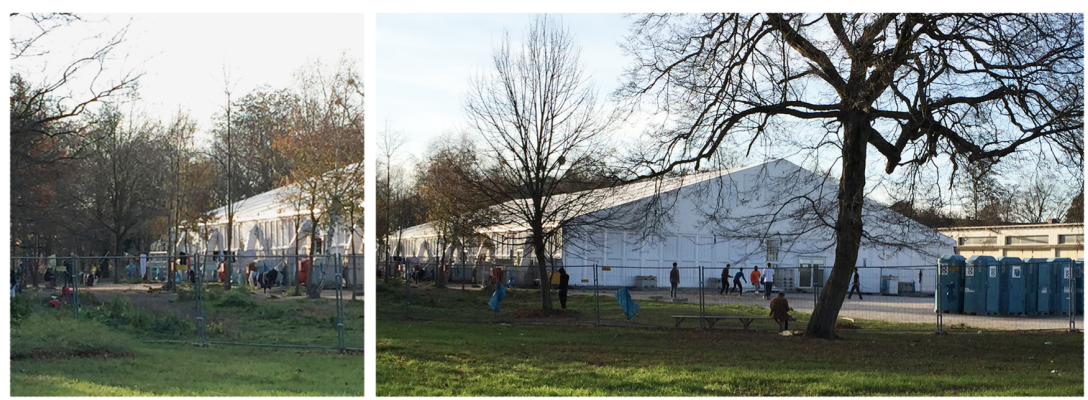

Figure 17: Picture of the refugee camp. The photo was taken right before participants in Exposure were elicited.

In total, due to the participants willingness to share, 735 euro could be invested into learning material for refugees at the refugee camp in Karlsruhe. This included dictionaries, books for learning German, writing material, and training material for children and adults (see Figure 18). Fostering language skills is crucial to enable refugees to participate in the labor market and partake in social life (Brücker et al., 2015). 

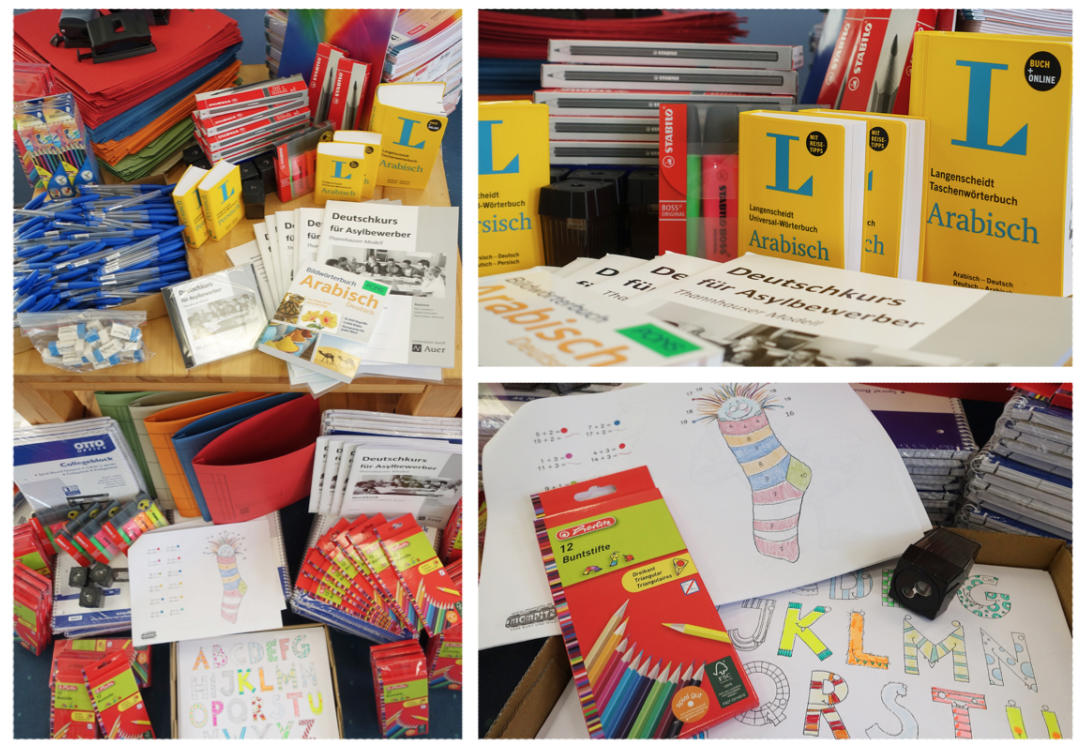

Figure 18: Donations for refugees. Due to the study, 735 euro could be invested into learning material for language courses at the refugee camp in Karlsruhe.

\subsubsection{Instructions}

Participants take their main decision, the sharing decision, after having followed different routes according to treatment. Thus, the instructions consisted of two parts: route description and main decision. Participants in the Exposure treatment have followed a route next to the refugee camp. Participants in the Proximity treatment take their decision in the same close physical distance to the camp but had not followed a route exposed to the refugee camp. Participants in the Distance treatment take their decision in a more remote location and had not seen the refugee camp on their way. Furthermore, all participants take part in an ex post socio-demographic questionnaire after the main sharing decision.

\section{Instructions for Main Decision in Proximity and Exposure}

Instructions for the main decision in Proximity and Exposure are identical and consist of three pages (compare Figure 19). 


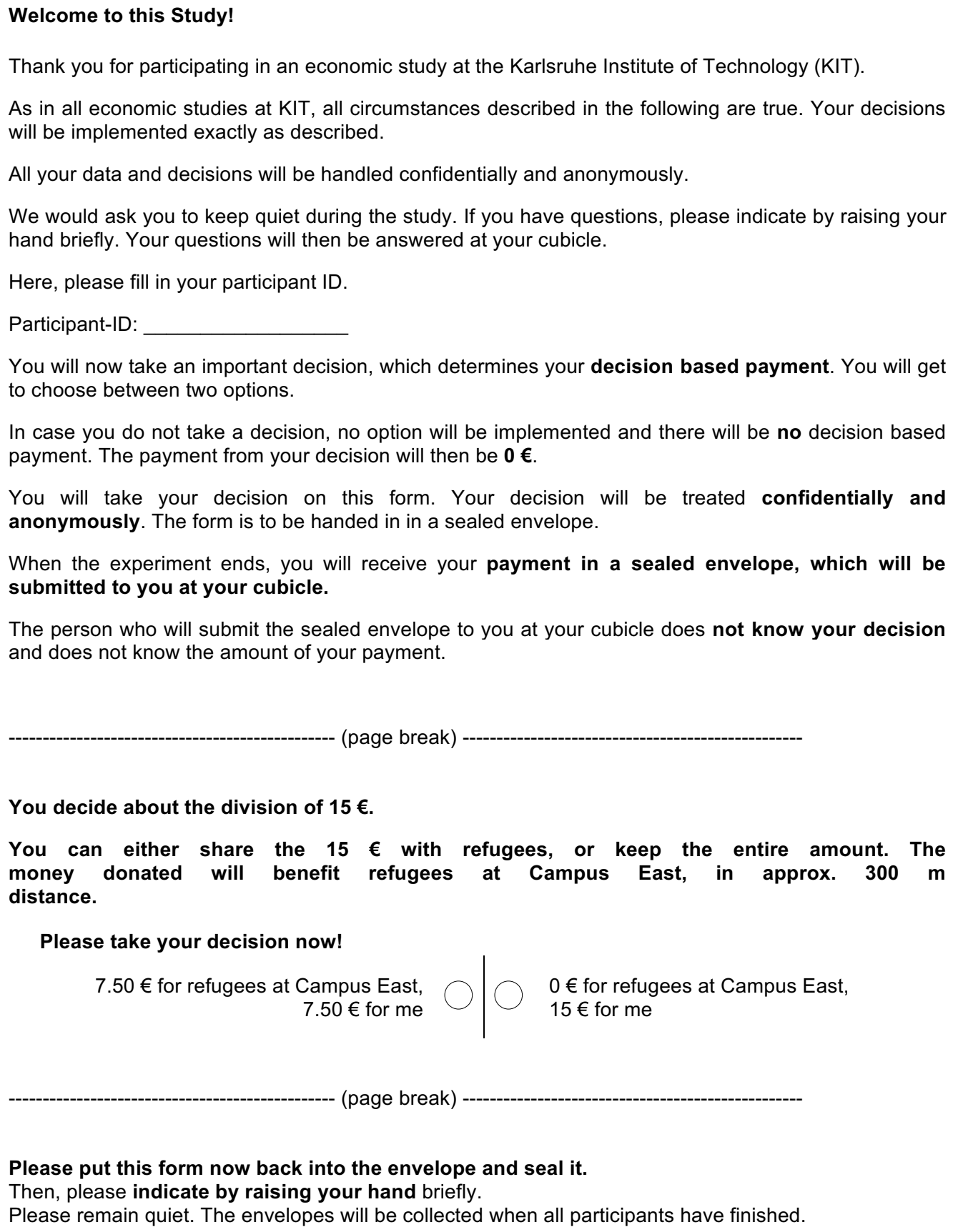

You decide about the division of $15 €$.

You can either share the $15 €$ with refugees, or keep the entire amount. The money donated will benefit refugees at Campus East, in approx. $300 \mathrm{~m}$ distance.

Please take your decision now!

$7.50 €$ for refugees at Campus East $7.50 €$ for me (page break)

Please put this form now back into the envelope and seal it. Then, please indicate by raising your hand briefly.

Please remain quiet. The envelopes will be collected when all participants have finished.

Figure 19: Instructions for main decision in Proximity and Exposure. 


\section{Instructions for Main Decision in Distance}

In Distance, participants take their decisions at a more remote location, approx. 2 miles $(3 \mathrm{~km})$ away from the camp instead of approx. 0.2 miles (300 $\mathrm{m})$, compare Figure 20. Except for the decision part itself, instructions of the main decision were identical to Proximity and Exposure.

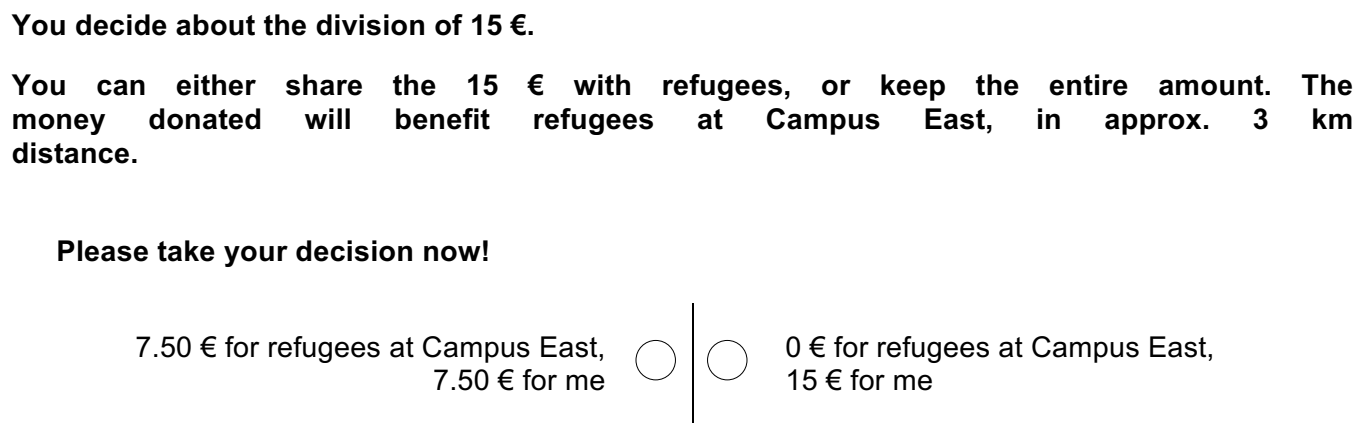

Figure 20: Instructions for main decision in Distance. 


\section{Instructions for Directions in Exposure}

In Exposure, directions lead participants alongside a local refugee camp on their way to the respective campus area (compare Figure 21).

Welcome and thank you for supporting our research by participating in this study!

This study is an investigation of KIT. The study will take place in the premises of KIT Campus East. To reach the location on foot will take you about 15 minutes. Simply for getting to Campus East, you will receive a reimbursement of $\mathbf{5} €$. Additionally, you will earn more money depending on your decisions within the study.

On the following page, you will find a map with directions from the lecture hall at Fasanengarten (HSaF) to Campus East. Please exactly follow these directions so that the study can start in time. All further information about the study you will receive in our premises at Campus East.

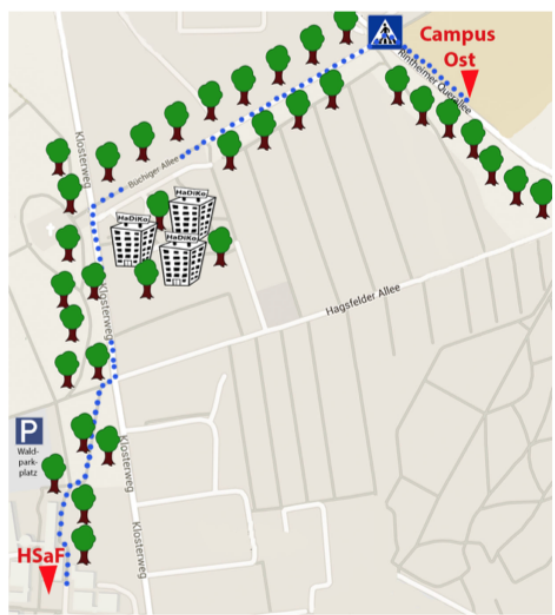

- From the lecture hall at Fasanengarten (HSaF), walk north. You will reach a small track. On this track, keep right until you reach the street Klosterweg.

- Follow Klosterweg in a northward direction, on your right, you will soon see the students' residence Hans-Dickmann-Kolleg (HaDiKo).

- Passing the HaDiKo turn right into Büchiger Allee. This is no road but only a walkway and cycle track.

- Follow Büchiger Allee until it crosses Rintheimer Querallee. Cross Rintheimer Querallee via the traffic island in the middle of the road to the sidewalk of Rintheimer Querallee on the other side.

- You are now on a walkway, please dismount in case you are riding a bike. Follow this sidewalk to the right.

- Stay on the sidewalk until on your left the entrance to Campus East appears.

- Pass the entrance and, in case you came by bike, lock it in the gate area. From now on, follow the signs saying "to the scientific study" until you reach the premises of the study.

Figure 21: Instructions for Directions in Exposure. 


\section{Instructions for Directions in Proximity}

In Proximity, instructions lead participants to the same campus entrance area as in Exposure but on a different route that does not allow the participants to see the camp on their way (compare Figure 22).

Welcome and thank you for supporting our research by participating in this study!

This study is an investigation of KIT. The study will take place in the premises of KIT Campus East. To reach the location on foot will take you about 15 minutes. Simply for getting to Campus East, you will receive a reimbursement of $\mathbf{5} €$. Additionally, you will earn more money depending on your decisions within the study.

On the following page, you will find a map with directions from the lecture hall at Fasanengarten (HSaF) to Campus East. Please exactly follow these directions so that the study can start in time. All further information about the study you will receive in our premises at Campus East.

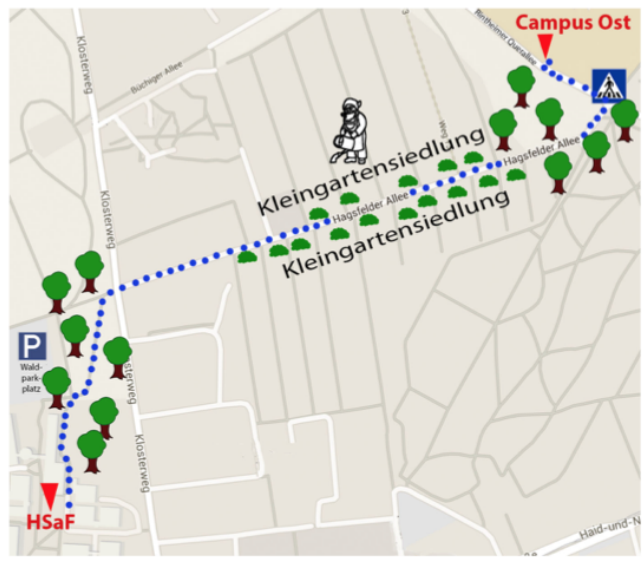

- From the lecture hall at Fasanengarten (HSaF), walk north. You will reach a small track. On this track, keep right until you reach the street Klosterweg.

- Cross Klosterweg right there, so that you reach Hagsfelder Allee.

- Follow Hagsfelder Allee. To your right and to your left, you will soon see garden plots [in German "Kleingartensiedlung"].

- The end of Hagsfelder Allee is surrounded by trees, before it crosses Rintheimer Querallee.

- Cross Rintheimer Querallee via the traffic island in the middle of the road to the sidewalk of Rintheimer Querallee on the other side.

- You are now on a walkway, please dismount in case you are riding a bike. Follow this sidewalk to the left.

- Stay on the sidewalk until on your right the entrance to Campus East appears.

- Pass the entrance and, in case you came by bike, lock it in the gate area. From now on, follow the signs saying "to the scientific study" until you reach the premises of the study.

Figure 22: Instructions for Directions in Proximity. 


\section{Instructions for Directions in Distance}

Directions in Distance lead the participants to another campus entrance area in a similar distance. The route does not allow participants to see the camp on their way (compare Figure 23).

Welcome and thank you for supporting our research by participating in this study!

This study is an investigation of KIT. The study will take place in the premises of KIT Campus East. To reach the location on foot will take you about 15 minutes. Simply for getting to Campus East, you will receive a reimbursement of $\mathbf{5} €$. Additionally, you will earn more money depending on your decisions within the study.

On the following page, you will find a map with directions from the lecture hall at Fasanengarten (HSaF) to Campus East. Please exactly follow these directions so that the study can start in time. All further information about the study you will receive in our premises at Campus East.

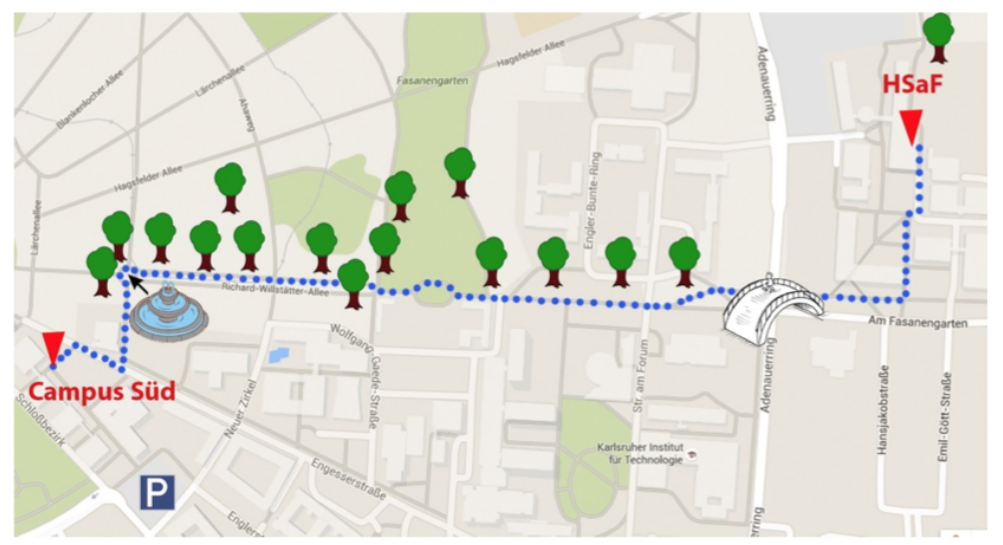

- From the lecture hall at Fasanengarten (HSaF), walk south. You will reach a walkway. Stay on this way until you reach a walkway parallel to the road Am Fasanengarten.

- Turn right and take the pedestrian bridge.

- Follow this way and keep straight on (following Richard-Willstätter-Allee).

- After some meters, there will be a big grassed area on your right. Stay on Richard-Willstätter-Allee until you reach a big fountain.

- After the Fountain, turn left and follow the walkway until you reach Engesserstraße.

- Now turn right into Engesserstraße and at the first opportunity, turn again to the left.

- Keep on walking some more meters until a stairway of a building at Campus South appears in front of you.

- Lock your bike to the bicycle rack near the stairway in case you came by bike. From now on, follow the signs saying "to the scientific study", until you reach the premises of the study.

Figure 23: Instructions for Directions in Proximity. 


\subsection{The Charity Paradigm}

In the following section of the appendix, we provide additional findings and information for the Charity Paradigm. As in section 5.1, this includes additional findings concerning personal differences, the analysis of ex-post arguments of the participants as well as a robustness check of our results. We provide further information concerning the experimental procedures and implementation of the Charity Paradigm in section 5.2 .2 as well as the translated instructions in the appendix section 5.2 .3 .

\subsubsection{Additional Findings and Discussion}

Donating to charity is correlated with a better emotional state. We find that participants who donate at least half their money to charity feel significantly better both right after the decision and at the very end of the study (two-sided t-test, $\mathrm{p}=0.007$ and $\mathrm{p}=0.018, \mathrm{n}=319$ and $\mathrm{n}=316$ respectively, compare Figure 24.

As in the field experiment, we find that cooperativeness is in line with general personality traits. Comparing highest vs. lowest quartiles (compare Figure 25), we find that openness $\left(\mathrm{p}=0.039^{* *}\right.$, one-sided t-test, $\left.\mathrm{n}=177\right)$ is correlated with a higher willingness to donate. Surprisingly, we do not find a statistically significant difference in willingness to donate for more agreeable participants $(\mathrm{p}=0.16$, one-sided t-test, $\mathrm{n}=178)$. We also find that more neurotic participants have a higher willingness to donate $\left(\mathrm{p}=0.049^{* *}\right.$, two-sided t-test, $n=166$ ) This difference can be explained by effects of gender, as it disappears when we control for gender. Females are known to score higher in neuroticism than males and also in our study, females have a significantly higher score in neuroticism (two-sided t-test females vs. males, $\mathrm{p}=0.000^{* * *}, \mathrm{n}=316$ ). We also elicit an empathy measure based on the interpersonal reactivity index IRI (compare Davis (1980); Paulus (2009)) and find a positive relationship between empathy measures and the willingness to donate $\left(\mathrm{p}=0.005^{* * *}\right.$, twosided t-test, $\mathrm{n}=320)$.

Eliciting various IQ measures, we find that cognitively skilled participants have a higher willingness to donate. We use the university entrance degree (Abitur) as one measure for cognitive skill (two-sided t-test of highest vs. lowest quartile, $\left.\mathrm{p}=0.0412^{* *}, \mathrm{n}=186\right)$. We also elicit a general intelligence measure based on fluid and crystalline intelligence. We use Ravens Advanced Progres- 


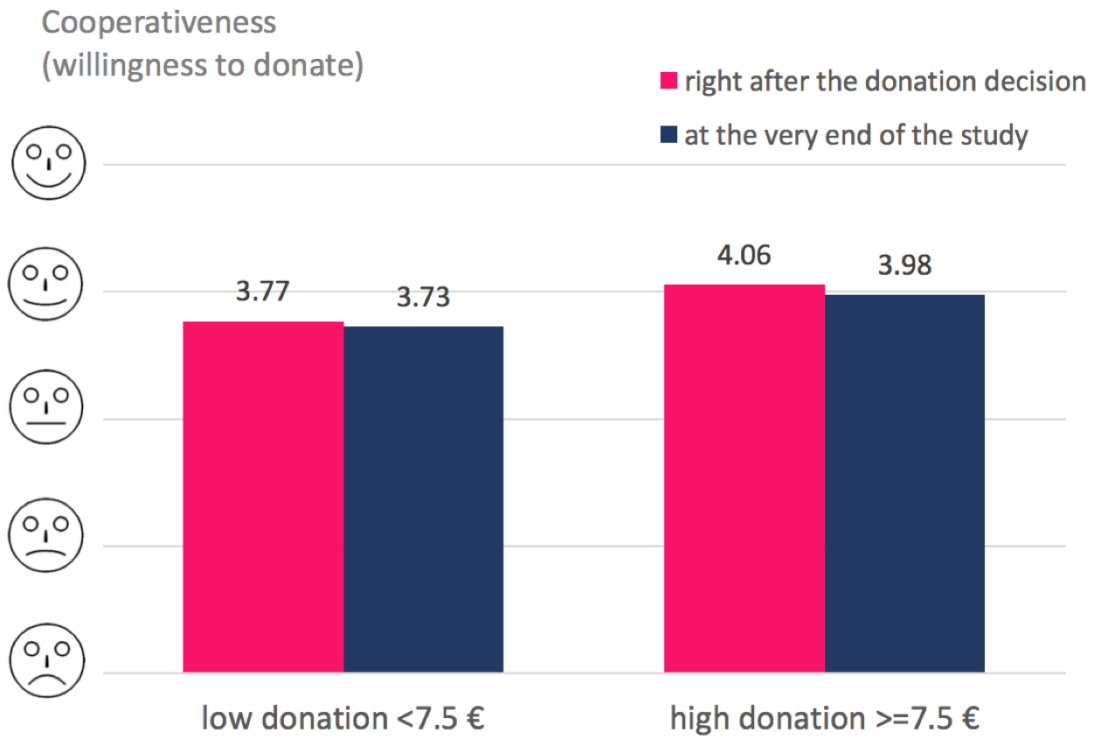

Figure 24: Emotional state right after the decision and at the very end of the study. The figure shows a happiness measure from 1 to 5 for participants who chose donations lower and higher than 7.50 euro - the equal split.

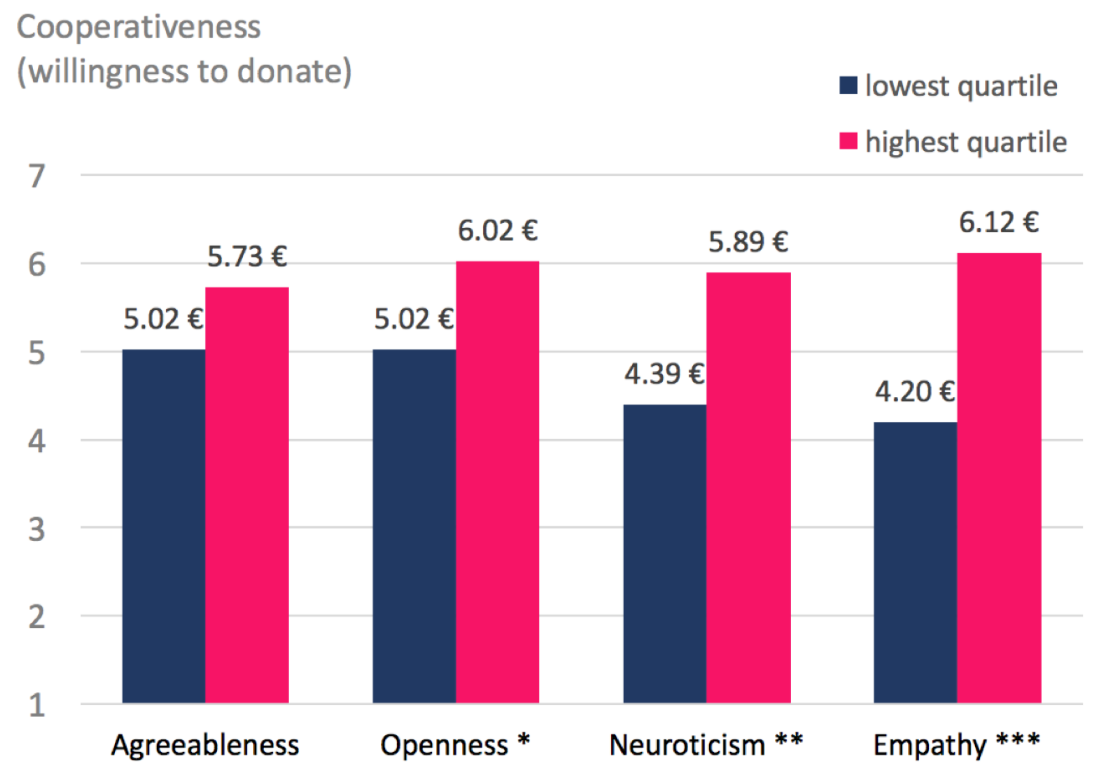

Figure 25: Personality traits and the willingness to donate. The figure shows mean donations of the most vs. least conscientious, open, neurotic, compassionate and military interventions refusing participants. 
sive Matrices Plus (Cattell, 1971) to measure fluid intelligence and a 12-item questionnaire for crystallized intelligence (Schipolowski et al., 2013). Also for this measure of intelligence, we find a significant difference in willingness to donate for the higher skilled vs. lower skilled participants (two-sided t-test, $\left.\mathrm{p}=0.068^{*}, \mathrm{n}=176\right)$. We do not find a significant effect for the overall impulsiveness measure based on Whiteside and Lynam (2001). Only one of the three items is correlated with a higher level of cooperativeness (two-sided t-test, $\mathrm{p}=0.008, \mathrm{n}=320$ ).

We find that a liberal political opinion and a positive attitude towards refugees and migrants is correlated with a higher willingness to donate. Participants in favor of the non-redistributive parties CSU, FDP and AFD have a significantly lower willingness to donate (3.46 euro vs. 5.68 euro, two-sided t-test, $\mathrm{p}=0.002^{* * *}, \mathrm{n}=312$, compare Figure 26).

Although the donation decision uses a completely unrelated context, we do find a correlation between a generally supporting attitude towards migrants and refugees (two-sided t-test, $\mathrm{p}=0.003^{* * *}, \mathrm{n}=185$ ) and refusing military interventions in the refugee crisis $(\mathrm{p}=0.003$, two-sided t-test, $\mathrm{n}=136)$ and the willingness to donate (compare Figure 27). Participants who feel compassionate about refugees also tend to donate more, but this difference is not significant (two-sided t-test, $\mathrm{p}=0.119, \mathrm{n}=320$ ). Maybe these opinions and attitudes towards refugees and migrants reflect a more general pacifist and prosocial attitude in the respective participants which could explain the higher cooperativeness towards people in need.

We find a structural break in the data when we compare the donation decision within the same city vs. another but comparable city. In the local treatments, cooperativeness decreases with increasing distance. For intermediate and large distances that apply to cities and regions outside of Karlsruhe, we do not find a statistically significant change in donation behavior with increasing distance (compare Figure 28).

Analysis of the participants justifications for the donation decision changes between treatments. Participants increasingly refer to a local responsibility in the larger distance treatments (compare Figure 29). Still, participants also increasingly use general and relatively generous norms and rules to make their decisions for larger distances (compare Figure 30).

Furthermore, mentioning substitutes for this specific donation of the study 


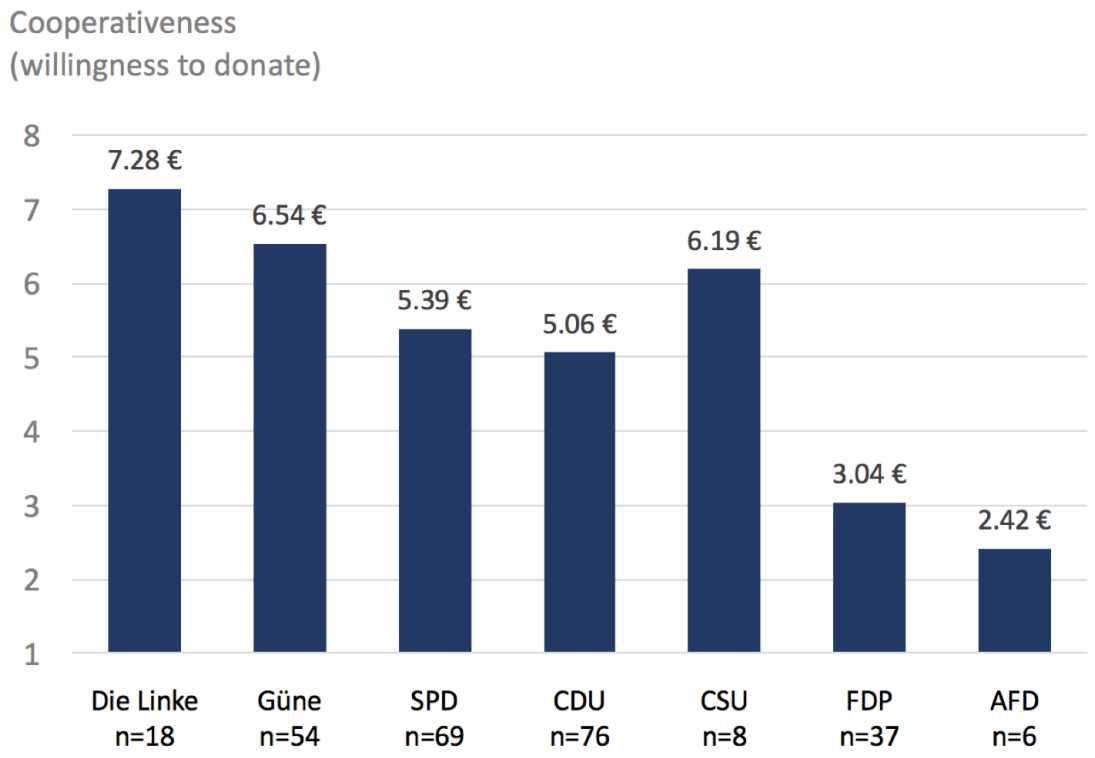

Figure 26: Political Orientation and willingness to donate. Parties are sorted from rather liberal and redistribute (Die Linke, Grüne) to rather conservative and non-redistributive (CSU, FDP, AFD).

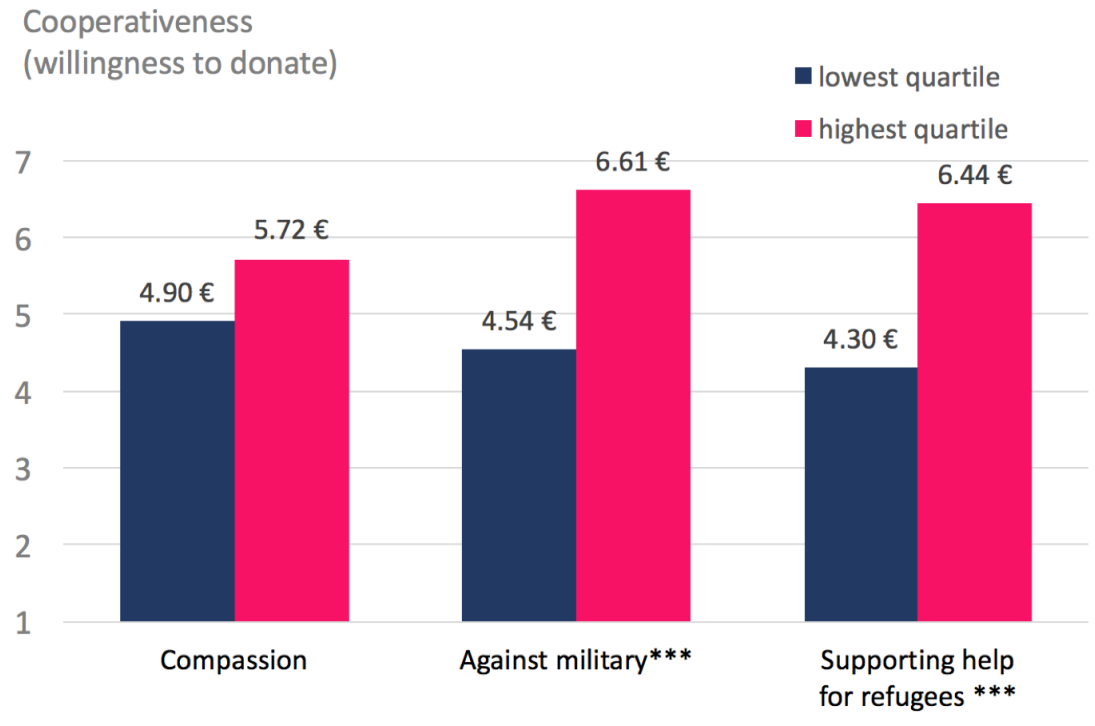

Figure 27: Political Opinions on refugees and migrants and willingness to donate. The figure shows the willingness to donate for most vs. least compassionate, supportive and pacifist participants. 


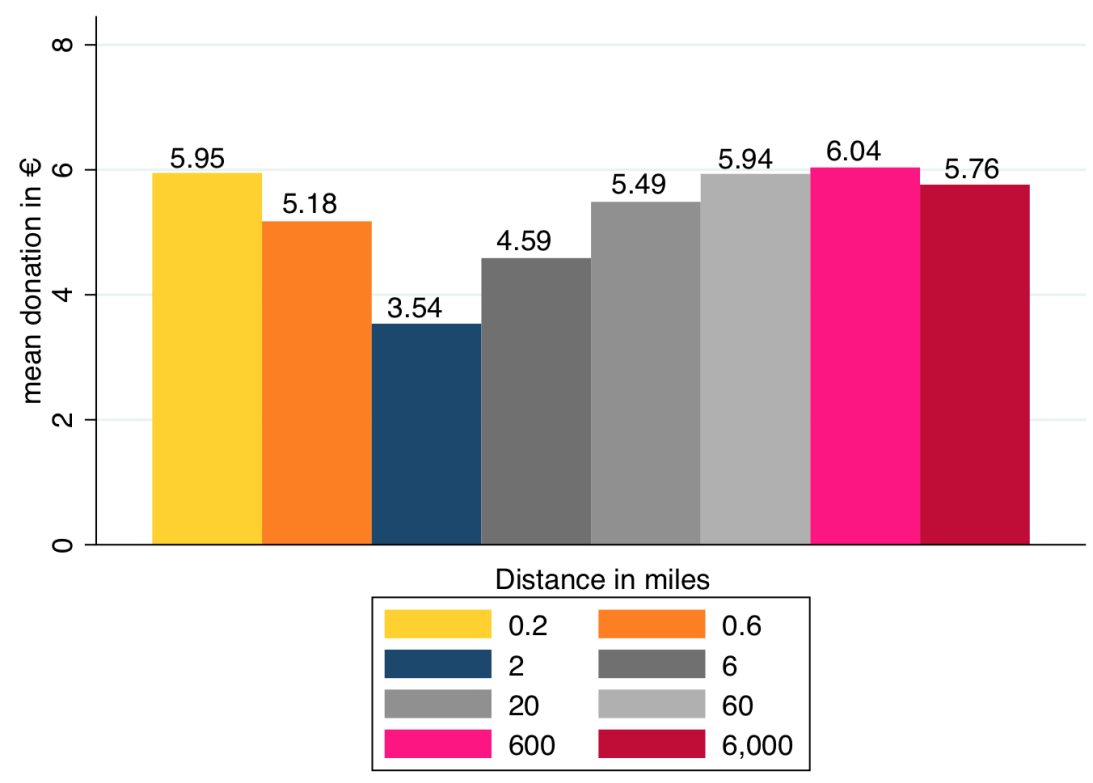

Figure 28: Charity Paradigm Donations of all treatments. The figure shows the willingness to donate in euro for all treatments in the Charity Paradigm.

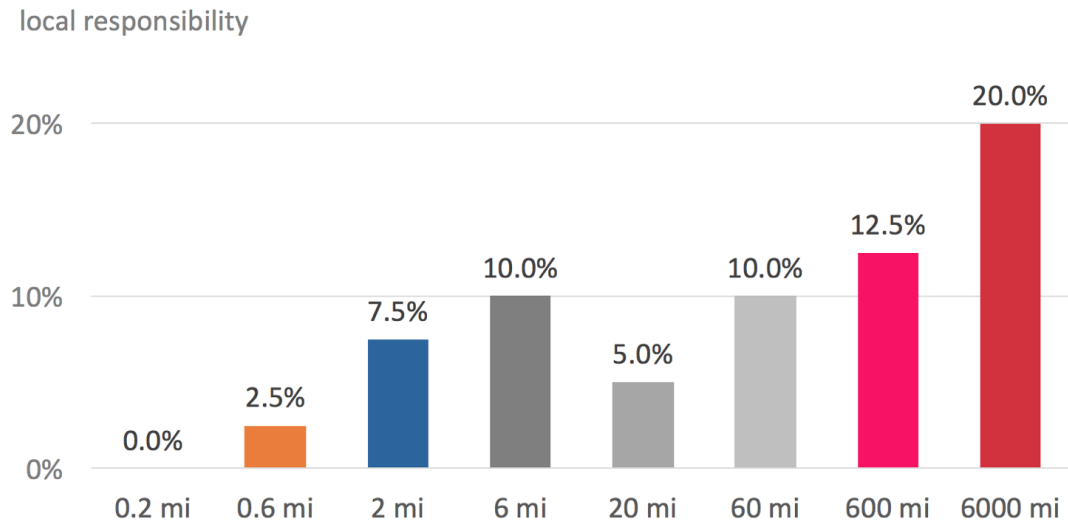

Figure 29: Local responsibility as justification. The figure shows the fractions of participants who referred to a local responsibility towards people in need when justifying their behavior. 


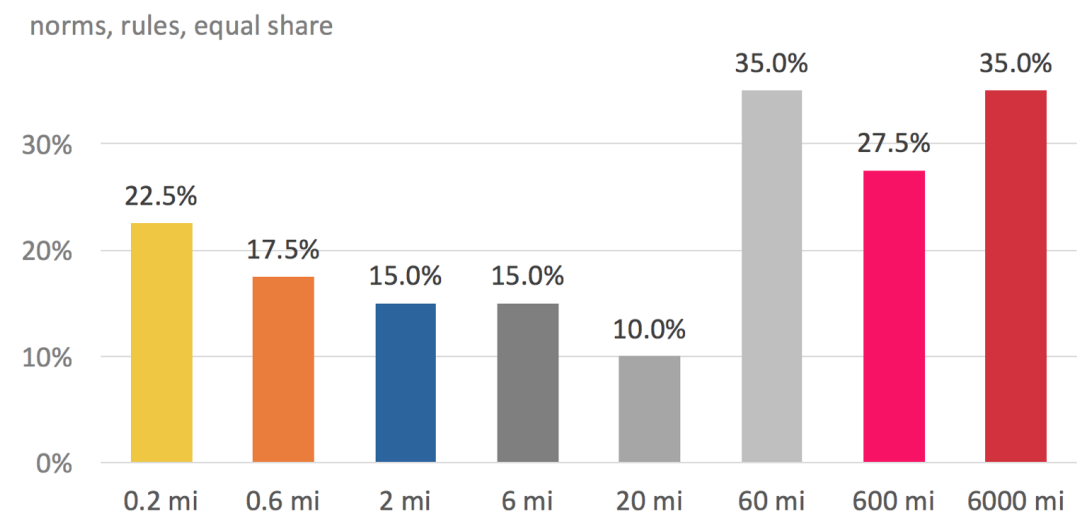

Figure 30: Norms and general rules as an explanation. The figure shows the fractions of participants who used norms (e.g. the equal share) and other general rules and reference points (like student wages) to explain their behavior.

shows a similar break like donation behavior. Participants less frequently come up with a preferred or actual substitute for the donation when people in need are either very close or very far away (compare Figure 31).

We conduct an OLS regression as a robustness check of our findings. We conducted an OLS regression that first ((1), (2)) focuses on overall cooperativeness and the correlation with personality traits (see Table 5). We do not find a strong and robust correlation between the personality traits agreeableness and openness with higher donation amounts in the Charity Paradigm. This is surprising, as these personality measures have repeatedly been associated with higher prosociality and altruistic behavior (compare e.g. Graziano et al. (2007); Oda et al. (2014)). Looking at personal differences, we find that gender does matter in the Charity Paradigm: males donate significantly lower amounts. This effect is in robust over all regressions and it is in line with literature on donation behavior (compare e.g. Eagly and Crowley (1986); Wiepking and Bekkers (2012)). Intelligence has been discussed to be a predictive factor for moral decision making (compare e.g. Loe et al. (2000); OFallon and Butterfield (2005)). In our data, we find that a higher IQ measure is correlated with more moral behavior, i.e. higher donation amounts in the Charity Paradigm. Controlling for political attitudes and political orientation, we find that the support of rather redistributive parties and a positive attitude towards refugees is positively correlated with a higher cooperativeness.

We further conduct a robustness check for the local treatments $((3),(4))$ as well as for all treatments including distances up to 6,000 miles $((5),(6))$. 


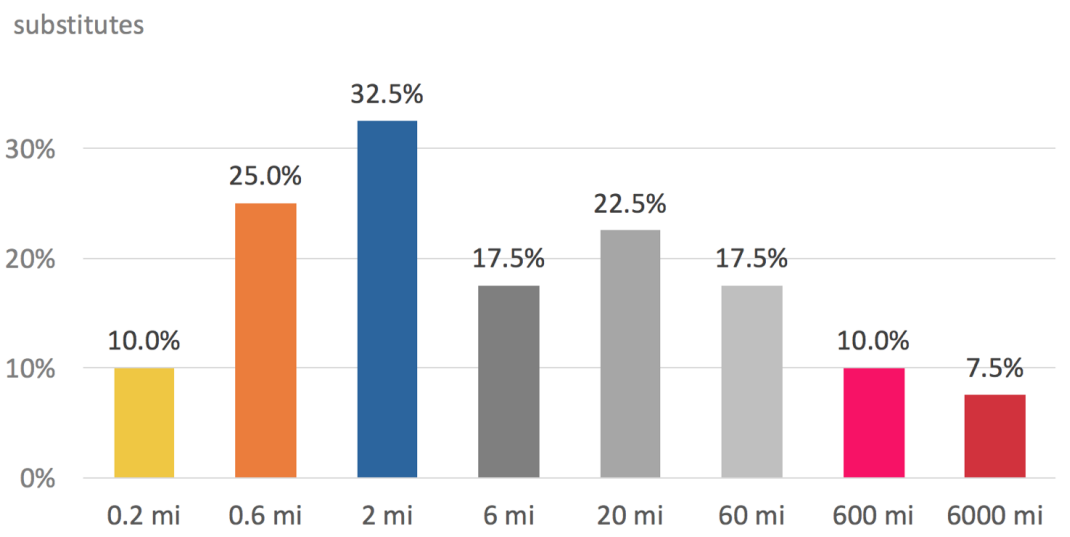

Figure 31: Substitutes for the donation as an explanation. The figure shows the fractions of participants who used substitutes (a different prior or planned donation or supportive behavior) to explain their behavior.

As we do not find a statistical difference in donation behavior for intermediate and large distances, we used a single variable for intermediate distances $(6 \mathrm{mi}$, $20 \mathrm{mi}$ and $60 \mathrm{mi}$ ) and another variable for large distances (600 $\mathrm{mi}$ and 6,000 $\mathrm{mi})$ in the latter regressions. The regression results demonstrate that the main effect is robust to a variety of control variables: Within local neighborhoods, physical distance matters significantly. 


\begin{tabular}{|c|c|c|c|c|c|c|}
\hline & \multicolumn{2}{|c|}{$\begin{array}{l}\text { personality and } \\
\text { overall cooperativeness }\end{array}$} & \multicolumn{2}{|c|}{$\begin{array}{l}\text { robustness check } \\
\text { local }\end{array}$} & \multicolumn{2}{|c|}{$\begin{array}{c}\text { robustness check } \\
\text { overall }\end{array}$} \\
\hline & (1) & (2) & (3) & $(4)$ & $(5)$ & (6) \\
\hline 0.6 miles & & & $\begin{array}{l}-0.775 \\
{[1.008]}\end{array}$ & $\begin{array}{l}-0.853 \\
{[1.043]}\end{array}$ & $\begin{array}{l}-0.786 \\
{[1.030]}\end{array}$ & $\begin{array}{l}-0.736 \\
{[1.012]}\end{array}$ \\
\hline 2 miles & & & $\begin{array}{l}-2.413^{\star \star} \\
{[1.008]}\end{array}$ & $\begin{array}{l}-2.211^{\star *} \\
{[1.025]}\end{array}$ & $\begin{array}{l}-2.347^{\star *} \\
{[1.020]}\end{array}$ & $\begin{array}{l}-1.988^{\star *} \\
{[0.997]}\end{array}$ \\
\hline intermediate distance & & & & & $\begin{array}{l}0.896 \\
{[0.832]}\end{array}$ & $\begin{array}{l}0.530 \\
0.816\end{array}$ \\
\hline large distance & & & & & $\begin{array}{l}-0.471 \\
{[0.896]} \\
\end{array}$ & $\begin{array}{l}-0.104 \\
{[0.882]}\end{array}$ \\
\hline agreeableness & $\begin{array}{l}0.001 \\
{[0.029]}\end{array}$ & $\begin{array}{l}-0.003 \\
{[0.028]}\end{array}$ & & $\begin{array}{l}0.009 \\
{[0.038]}\end{array}$ & $\begin{array}{l}0.002 \\
{[0.029]}\end{array}$ & $\begin{array}{l}-0.003 \\
{[0.028]}\end{array}$ \\
\hline openness & $\begin{array}{l}0.061^{*} \\
{[0.034]}\end{array}$ & $\begin{array}{l}0.054 \\
{[0.035]}\end{array}$ & & $\begin{array}{l}0.490 \\
{[0.059]}\end{array}$ & $\begin{array}{l}0.064^{*} \\
{[0.035]}\end{array}$ & $\begin{array}{l}0.055 \\
{[0.036]}\end{array}$ \\
\hline IQ (-) & $\begin{array}{l}-.0997^{\star \star} \\
{[0.479]}\end{array}$ & $\begin{array}{l}-0.905^{\star} \\
{[0.470]}\end{array}$ & & $\begin{array}{l}-1.322^{*} \\
{[0.764]}\end{array}$ & $\begin{array}{l}-0.878^{\star} \\
{[0.483]}\end{array}$ & $\begin{array}{l}-0.797^{\star} \\
{[0.474]}\end{array}$ \\
\hline male & $\begin{array}{l}-1.501^{\star \star \star} \\
{[0.515]}\end{array}$ & $\begin{array}{l}-1.234^{\star \star} \\
{[0.513]}\end{array}$ & & $\begin{array}{l}-2.039^{\star \star} \\
{[0.848]}\end{array}$ & $\begin{array}{l}-1.455^{\star \star \star} \\
{[0.515]}\end{array}$ & $\begin{array}{l}-1.189^{\star \star} \\
{[0.513]}\end{array}$ \\
\hline military & & $\begin{array}{l}-0.252 \\
{[0.168]}\end{array}$ & & & & $\begin{array}{l}-0.250 \\
{[0.168]}\end{array}$ \\
\hline less redistributive party & & $\begin{array}{l}-1.757^{\star *} \\
{[0.711]}\end{array}$ & & & & $\begin{array}{l}-1.720^{\star *} \\
{[0.710]}\end{array}$ \\
\hline supporting help for refugees & & $\begin{array}{l}0.107^{\star *} \\
{[0.054]}\end{array}$ & & & & $\begin{array}{l}0.102^{\star} \\
{[0.054]}\end{array}$ \\
\hline Constant & $\begin{array}{l}6.434^{\star \star \star} \\
{[2.495]}\end{array}$ & $\begin{array}{l}5.260^{\star *} \\
{[2.666]}\end{array}$ & $\begin{array}{l}5.950^{\star \star \star} \\
{[0.713]}\end{array}$ & $\begin{array}{l}9.298^{\star \star} \\
{[3.928]}\end{array}$ & $\begin{array}{l}5.849^{\star \star} \\
{[2.588]}\end{array}$ & $\begin{array}{l}5.100^{\star} \\
{[2.757]}\end{array}$ \\
\hline Prob > F & $0.003^{\star \star \star}$ & $0.000^{*}$ & $0.054^{*}$ & $0.032^{\star \star *}$ & $0.005^{\star \star \star}$ & 0.000 \\
\hline $\mathrm{R}^{2}$ & 0.051 & 0.108 & 0.049 & 0.117 & 0.071 & 0.125 \\
\hline observations & 307 & 303 & 120 & 116 & 307 & 303 \\
\hline
\end{tabular}

Table 5: Validity and robustness check. The table displays OLS regression coefficients (donation in euro as dependent variable), standard errors in brackets. $* * * / * * / *$ indicate significance on a $1-/ 5-/ 10$-percent level respectively.

\subsubsection{Procedures}

The lab experiment took place between March and May 2017 in the Karlsruhe Decision and Design Lab in Karlsruhe, Germany. It was conducted in a controlled, randomized and gender-controlled manner. As in the field experiment, we used a paper-pencil approach to conduct the data. Anonymity of the participants was carefully ensured and emphasized. 
We used the software HROOT to recruit participants for this study (Bock et al., 2014). With a total of ten sessions, we collected data from 320 participants (55\% males). Overall duration per session was about 60 minutes. Participants could earn up to 15 euro by participating in this study.

\subsubsection{Instructions}

Participants took their main decision, the sharing decision, in an anonymous setting in the KD2Lab in Karlsruhe. The instructions were in most parts identical across treatments. Only the specifications of the distance towards the people in need were different in each treatment and the reference to Karlsruhe was adapted for the local treatments (up to 2 miles) and the larger distance treatments (6 miles and more, referring to different city than Karlsruhe). After the main decision, all participants took part in an ex post socio-demographic questionnaire.

We provide two examples for the instructions. The first example shows the instructions for the 0.2 miles treatment and shows how the information was presented in the low distance treatments within the same city. The second example shows the instructions for the larger distance treatment of 6,000 miles which includes information about comparability of the respective regions with the city of Karlsruhe. For each treatment within these two categories, only the specification of the distance (e.g. "6 miles") was adapted and changed. 
Welcome to this Study!

Thank you for participating in an economic study at the Karlsruhe Institute of Technology (KIT).

As in all economic studies at KIT, all circumstances described in the following are true. Your decisions will be implemented exactly as described.

All your data and decisions will be handled confidentially and anonymously.

We would ask you to keep quiet during the study. If you have questions, please indicate by using the signs in the back of your cubicle. Your questions will then be answered at your cubicle as soon as possible.

You will now take an important decision, which determines your payment. You will get to choose between different options. In case you do not take a decision, the first option will be implemented and your payment will be $0 €$.

You will take your decision on your answer sheet. Your decision will be treated confidentially and anonymously. The form is to be handed in in a sealed envelope.

When the experiment ends, you will receive your payment in a sealed envelope, which will be submitted to you at your cubicle.

The person who will submit the sealed envelope to you at your cubicle does not know your decision and does not know the amount of your payment.

(page break)

Here, please fill in your participant ID.

Participant-ID:

Within the scope of this experiment, $15 €$ shall be donated to benefit people in need in approx. $0.2 \mathrm{mi}$ distance.

You have the possibility to claim a portion of the $15 €$ as your payment. In case you decide to do so, this portion will be deducted from the $15 €$ and you will receive the money at the end of the study.

The remaining money will benefit people in need in approx. 0.2 mi distance.

Please take your decision on the back side of this sheet.

(page break)

Figure 32: Instructions for local treatments.

The figure show the example of 0.2 miles (part $1 / 2$ ). 
Please indicate, which option is to be implemented.

\begin{tabular}{|c|c|c|}
\hline $\begin{array}{c}\text { Your } \\
\text { decision } \\
\text { (one tick) }\end{array}$ & Your payment & $\begin{array}{c}\text { Payment for people } \\
\text { in need in approx. 0.2 mi } \\
\text { distance }\end{array}$ \\
\hline$\square$ & $0,00 €$ & $15,00 €-0,00 €=15,00 €$ \\
\hline$\square$ & $0,50 €$ & $15,00 €-0,50 €=\mathbf{1 4 , 5 0} €$ \\
\hline$\square$ & $1,00 €$ & $15,00 €-1,00 €=\mathbf{1 4 , 0 0} €$ \\
\hline$\square$ & $1,50 €$ & $15,00 €-1,50 €=\mathbf{1 3 , 5 0} €$ \\
\hline$\cdots$ & $\ldots$ & $\cdots$ \\
\hline$\square$ & $14,50 €$ & $15,00 €-14,50 €=\mathbf{0 , 5 0} €$ \\
\hline$\square$ & $15,00 €$ & $15,00 €-15,00 €=\mathbf{0 , 0 0} €$ \\
\hline
\end{tabular}

Please put the completed form back into the envelope and then indicate with the signs in the back of your cubicle that you are done. The envelopes will be collected as soon as all participants have finished. Afterwards you will be asked to answer a few questions anonymously.

Figure 33: Instructions for local treatments.

The figure show the example of 0.2 miles (part 2/2). 


\section{Welcome to this Study!}

Thank you for participating in an economic study at the Karlsruhe Institute of Technology (KIT).

As in all economic studies at KIT, all circumstances described in the following are true. Your decisions will be implemented exactly as described.

All your data and decisions will be handled confidentially and anonymously.

We would ask you to keep quiet during the study. If you have questions, please indicate by using the signs in the back of your cubicle. Your questions will then be answered at your cubicle as soon as possible.

You will now take an important decision, which determines your payment. You will get to choose between different options. In case you do not take a decision, the first option will be implemented and your payment will be $0 €$.

You will take your decision on your answer sheet. Your decision will be treated confidentially and anonymously. The form is to be handed in in a sealed envelope.

When the experiment ends, you will receive your payment in a sealed envelope, which will be submitted to you at your cubicle.

The person who will submit the sealed envelope to you at your cubicle does not know your decision and does not know the amount of your payment.

(page break)

Here, please fill in your participant ID.

Participant-ID:

Within the scope of this experiment, $15 €$ shall be donated to benefit people in need in a city with comparable prosperity like Karlsruhe* in approx. 6,000 mi distance.

You have the possibility to claim a portion of the $15 €$ as your payment. In case you decide to do so, this portion will be deducted from the $15 €$ and you will receive the money at the end of the study.

The remaining money will benefit people in need in a city with comparable prosperity like Karlsruhe* in approx. 6,000 mi distance.

Please take your decision on the back side of this sheet.

--- (footnote) ----

* according to unemployment rate and GDP per capita of the respective region

(page break)

Figure 34: Instructions for intermediate and large distance treatments. The figure shows the example of 6,000 miles (part 1/2). 
Please indicate, which option is to be implemented.

\begin{tabular}{|c|c|c|}
\hline $\begin{array}{c}\text { Your } \\
\text { decision } \\
\text { (one tick) }\end{array}$ & Your payment & $\begin{array}{c}\text { Payment for people } \\
\text { in need in approx. 6,000 mi } \\
\text { distance }\end{array}$ \\
\hline$\square$ & $0,00 €$ & $15,00 €-0,00 €=15,00 €$ \\
\hline$\square$ & $0,50 €$ & $15,00 €-0,50 €=14,50 €$ \\
\hline$\square$ & $1,00 €$ & $15,00 €-1,00 €=14,00 €$ \\
\hline$\square$ & $1,50 €$ & $15,00 €-1,50 €=13,50 €$ \\
\hline$\cdots$ & $\ldots$ & $\ldots$ \\
\hline$\square$ & $14,50 €$ & $15,00 €-14,50 €=\mathbf{0 , 5 0} €$ \\
\hline$\square$ & $15,00 €$ & $15,00 €-15,00 €=\mathbf{0 , 0 0} €$ \\
\hline
\end{tabular}

Please put the completed form back into the envelope and then indicate with the signs in the back of your cubicle that you are done. The envelopes will be collected as soon as all participants have finished. Afterwards you will be asked to answer a few questions anonymously.

Figure 35: Instructions for intermediate and large distance treatments. The figure shows the example of 6,000 miles (part 2/2). 


\section{References}

Akrami, N., B. Ekehammar, and R. Bergh (2010). Generalized Prejudice: Common and Specific Components. Psychological Science 22(1), 57-59.

Allport, G. W. and H. S. Odbert (1936). Trait-names: A psycho-lexical study. Psychological Monographs 47(1), i-171.

Bock, O., I. Baetge, and A. Nicklisch (2014). hroot: Hamburg Registration and Organization Online Tool. European Economic Review 71, 117-120.

Brücker, H., A. Hauptmann, and P. Trübswetter (2015). Aktuelle Berichte Asyl- und Flüchtlingsmigration in die EU und nach Deutschland 8/2015. http://doku.iab.de/aktuell/2015/aktueller_bericht_1508.pdf, last accessed November 2016.

Cattell, R. B. (1971). The Structure of Intelligence in Relation to the NatureNurture Controversy. Intelligence: Genetic and Environmental Influences, pp. 3-30. Grune and Stratton.

Davis, M. H. (1980). A multidimensional approach to individual differences in empathy. Volume 10 of JSAS Catalog of Selected Documents in Psychology, pp. 85. American Psychological Association Washington, DC.

Eagly, A. H. and M. Crowley (1986). Gender and Helping Behavior: A MetaAnalytic Review of the Social Psychological Literature. Psychological Bulletin 100(3), 309-330.

Ekehammar, B. and N. Akrami (2003). The Relation between Personality and Prejudice: A Variable- and a Person-Centred Approach. European Journal of Personality 17(6), 449-464.

Fessler, D. M., H. C. Barrett, M. Kanovsky, S. Stich, C. Holbrook, J. Henrich, A. H. Bolyanatz, M. M. Gervais, M. Gurven, G. Kushnick, A. C. Pisor, C. von Rueden, and S. Laurence (2015). Moral parochialism and contextual contingency across seven societies. Proceedings of the Royal Society B Biological Sciences 282(1813), 20150907.

Festinger, L. (1962). A Theory of Cognitive Dissonance, Volume 2. Stanford University Press.

Gallego, A. and S. Pardos-Prado (2014). The Big Five Personality Traits and Attitudes towards Immigrants. Journal of Ethnic and Migration Studies $40(1), 79-99$. 
Graziano, W. G., M. M. Habashi, B. E. Sheese, and R. M. Tobin (2007). Agreeableness, Empathy, and Helping: A Person $\times$ Situation Perspective. Journal of Personality and Social Psychology 93(4), 583-599.

Greiner, B. (2015). Subject Pool Recruitment Procedures: Organizing Experiments With ORSEE. Journal of the Economic Science Association 1(1), $114-125$.

Kajonius, P. (2014). The Effect of Information Overload on Charity Donations. International Journal of Psychology and Behavioral Sciences 4(1), 41-50.

Kovaleva, A., C. Beierlein, C. J. Kemper, and B. Rammstedt (2012). Eine Kurzskala zur Messung von Impulsivität nach dem UPPSAnsatz: Die Skala Impulsives-Verhalten-8 (I-8). Working paper. http://www.christoph-kemper.net/fileadmin/user_upload/Publications/ Kovelava_Beierlein__Kemper___Rammstedt__2012__Impulsivitaet-I-8.pdf, last accessed November 2016.

Loe, T. W., L. Ferrell, and P. Mansfield (2000). A Review of Empirical Studies Assessing Ethical Decision Making in Business. Journal of Business Ethics 25(3), 185-204.

Millet, K. and S. Dewitte (2007). Altruistic Behavior as a Costly Signal of General Intelligence. Journal of Research in Personality 41(2), 316-326.

Oda, R., W. Machii, S. Takagi, Y. Kato, M. Takeda, T. Kiyonari, Y. Fukukawa, and K. Hiraishi (2014). Personality and Altruism in Daily Life. Personality and Individual Differences 56, 206-209.

OFallon, M. J. and K. D. Butterfield (2005). A Review of the Empirical Ethical Decision-Making Literature: 1996-2003. Journal of Business Ethics 59(4), 375-413.

Paulus, C. (2009). Der Saarbrücker Persönlichkeitsfragebogen SPF (IRI) zur Messung von Empathie: Psychometrische Evaluation der deutschen Version des Interpersonal Reactivity Index. Technical report, Universität des Saarlandes. http://hdl.handle.net/20.500.11780/3343, last accessed July 2017.

Satow, L. (2012). Big-Five-Persönlichkeitstest (B5T). Technical report, Zentrum für Psychologische Information und Dokumentation ZPID. https:// www.zpid.de/pub/tests/PT_9006357_B5T_Forschungsbericht.pdf, last accessed November 2016. 
Schipolowski, S., O. Wilhelm, U. Schroeders, A. Kovaleva, C. J. Kemper, and B. Rammstedt (2013). BEFKI GC-K: A Short Scale for the Measurement of Crystallized Intelligence. Methoden, Daten, Analysen (mda) 7(2), 153-181.

Whiteside, S. P. and D. R. Lynam (2001). The Five Factor Model and Impulsivity: Using a Structural Model of Personality to Understand Impulsivity. Personality and Individual Differences 30(4), 669-689.

Wiepking, P. and R. Bekkers (2012). Who Gives? A Literature Review of Predictors of Charitable Giving. Part Two: Gender, Family Composition and Income. Voluntary Sector Review 3(2), 217-245. 


\section{Working Paper Series in Economics}

recent issues

No. 110 Leonie Kühl and Nora Szech: Physical distance and cooperativeness towards strangers, November 2017

No. 109 Deniz Dizdar, Benny Moldovanu and Nora Szech: The multiplier effect in two-sided markets with bilateral investments, November 2017

No. 108 Andranik S. Tangian: Policy representation by the 2017 Bundestag, September 2017

No. 107 Andranik S. Tangian: Policy representation by German parties at the 2017 federal election, September 2017

No. 106 Andranik S. Tangian: Design and results of the third vote experiment during the 2017 election of the Karlsruhe Institute of Technology student parliament, September 2017

No. 105 Markus Fels: Incentivizing efficient utilization without reducing access: The case against cost-sharing in insurance, July 2017

No. 104 Andranik S. Tangian: Declining labor-labor exchange rates as a cause of inequality growth, July 2017

No. 103 Konstanze Albrecht, Florentin Krämer and Nora Szech: Animal welfare and human ethics: A personality study, June 2017

No. 102 Jannis Engel and Nora Szech: A little good is good enough: Ethical consumption, cheap excuses, and moral self-licensing, March 2017

No. 101 David Freeman, Erik O. Kimbrough, J. Philipp Reiss: Opportunity cost, inattention and the bidder's curse, February 2017

No. 100 Andranik S. Tangian: Selection of questions for VAAs and the VAA-based elections, January 2017 